\title{
ESensitivity of Forecast Uncertainty to Different Microphysics Schemes within a Convection-Allowing Ensemble during SoWMEX-IOP8
}

\author{
Chin-Hung Chen, ${ }^{\mathrm{a}}$ KAO-Shen Chung, ${ }^{\mathrm{a}}$ SHU-ChiH YAng, ${ }^{\mathrm{a}, \mathrm{b}}$ Li-Hsin Chen, ${ }^{\mathrm{a}}$ PAY-LiAm Lin, ${ }^{\mathrm{a}}$ AND \\ RYAN D. TORN ${ }^{\mathrm{c}}$ \\ ${ }^{a}$ Department of Atmospheric Sciences, National Central University, Taoyuan City, Taiwan \\ ${ }^{\mathrm{b}}$ RIKEN Center for Computational Science, Kobe, Japan \\ ${ }^{\mathrm{c}}$ Department of Atmospheric and Environmental Sciences, University at Albany, State University of New York, Albany, New York
}

(Manuscript received 3 November 2020, in final form 2 November 2021)

\begin{abstract}
A mesoscale convective system that occurred in southwestern Taiwan on 15 June 2008 is simulated using convection-allowing ensemble forecasts to investigate the forecast uncertainty associated with four microphysics schemes - the Goddard Cumulus Ensemble (GCE), Morrison (MOR), WRF single-moment 6-class (WSM6), and WRF double-moment 6-class (WDM6) schemes. First, the essential features of the convective structure, hydrometeor distribution, and microphysical tendencies for the different microphysics schemes are presented through deterministic forecasts. Second, ensemble forecasts with the same initial conditions are employed to estimate the forecast uncertainty produced by the different ensembles with the fixed microphysics scheme. GCE has the largest spread in most state variables due to its most efficient phase conversion between water species. By contrast, MOR results in the least spread. WSM6 and WDM6 have similar vertical spread structures due to their similar ice-phase formulas. However, WDM6 produces more ensemble spread than WSM6 does below the melting layer, resulting from its double-moment treatment of warm rain processes. The model simulations with the four microphysics schemes demonstrate upscale error growth through spectrum analysis of the root-mean difference total energy (RMDTE). The RMDTE results reveal that the GCE and WDM6 schemes are more sensitive to initial condition uncertainty, whereas the MOR and WSM6 schemes are relatively less sensitive to that for this event. Overall, the diabatic heating-cooling processes connect the convective-scale cloud microphysical processes to the large-scale dynamical and thermodynamical fields, and they significantly affect the forecast error signatures in the multiscale weather system.
\end{abstract}

KEYWORDS: Cloud microphysics; Ensembles; Mesoscale forecasting; Cloud parameterizations; Numerical weather prediction/forecasting

\section{Introduction}

The accuracy of numerical weather prediction (NWP) is intrinsically limited due to forecast uncertainty. The primary sources are errors in the initial conditions of the state variables and model errors due to subgrid physics parameterizations. The design of ensemble prediction systems aims to account for this uncertainty by using multiple simulations with slight differences in initial conditions or model configurations to capture the possible range of future atmospheric states. Also, to improve the quality of initial conditions and obtain optimal forecasts, extensive effort has been invested into the development of data assimilation techniques, in which optimal estimation methods are employed to obtain the most favorable initial conditions by adjusting the model state toward the observations. Regarding the ensemble-based data assimilation approach, several studies have shown that an ensemble Kalman filter (EnKF; Evensen 1994) improves the initial conditions for meso- and small-scale analysis (e.g.,

¿Denotes content that is immediately available upon publication as open access.

Corresponding author: Kao-Shen Chung, kaoshen.chung@ gmail.com; kschung@atm.ncu.edu.tw
Snyder and Zhang 2003; Xue et al. 2010; Dowell et al. 2011; Meng and Zhang 2007; Yang et al. 2020; You et al. 2020). An EnKF uses ensemble predictions to estimate the background error statistics and determine how to spread observed information to correct the model state. A favorable ensemble should have a mean that approaches reality and an ensemble prediction range that represents the forecast uncertainty. Because the error variance is associated with ensemble spread, an underdispersive ensemble may limit the effectiveness of assimilating observations in an EnKF.

Initial condition perturbation is often used to address initial condition errors and investigate the evolution of forecast uncertainty. For example, Zhang (2005) utilized various initial condition perturbations to show that moist convection plays a vital role in the rapid growth of small-scale errors, which strongly influence mesoscale predictability (Zhang 2005; Selz and Craig 2015). Regarding convective-scale ensemble forecasts, small-scale errors tend to be highly amplified in areas of convective instability (Chung et al. 2013; Nielsen and Schumacher 2016). Therefore, apart from initial condition perturbations, model physics uncertainty additionally plays a role in accounting for forecast uncertainty (Romine et al. 2014; Tapiador et al. 2012; Li et al. 2020). Methods such as multiphysics schemes (Meng and Zhang 2007; Schumacher and Clark 2014; Ha et al. 2015), multiparameter ensembles within a specific scheme (Duda et al. 2014; Yussouf and Stensrud 
2012), and stochastic physics schemes (Romine et al. 2014; Lupo et al. 2020) have been proposed to account for model errors and obtain the full benefits of ensemble forecasts. The multiphysics approach, in which different physics parameterizations are employed in an ensemble, is commonly used and has consistently improved ensemble dispersion (Schumacher and Clark 2014; Stensrud et al. 2000). Although this method is straightforward and feasible to implement, how each physics scheme contributes to the overall forecast uncertainty is unclear.

In particular, microphysics schemes that explicitly represent moist convection strongly impact convective-scale simulations (Putnam et al. 2017b; Gilmore et al. 2004). Different microphysics schemes can produce highly distinct convection signatures because of variations in the parameterization of the phase change between water vapor and cloud/precipitation particles. The formulations of cloud condensation nuclei and ice nuclei activation from water vapor may also affect the latent heating-cooling structure and convective fluxes. Considerable uncertainties exist in the representation of ice-phase processes, such as the appropriate number and type of ice-phase categories (Morrison et al. 2020). As Morrison and Milbrandt (2011) demonstrated, the structure of a simulated storm is sensitive to the assumption regarding the type of rimed ice (graupel or hail). Moreover, varying the ice-phase parameters can result in specific forecast outcomes. For instance, Gilmore et al. (2004) used a simple liquid-ice scheme and showed that the precipitation and vertical velocity in an idealized storm simulation are highly sensitive to the graupel intercept parameter and density variation. Thus, intrinsic variation in different microphysics schemes (or within the same scheme) often leads to considerable variations in NWP forecasts. Combining several microphysics schemes helps to account for their uncertainty. However, in most multiphysics ensembles, the benefits of mixing different microphysics schemes are embedded with other varied physics schemes. Therefore, each of microphysics contribution, which is crucial in convective-scale simulations, to the total forecast uncertainty has not been fully explored.

At present, a gamma distribution function (Ulbrich 1983) [Eq. (1)] is generally used in bulk microphysics schemes to represent the particle size distribution of water species through the intercept, slope, and shape parameters. In the single-moment scheme, the slope parameter is controlled by predicting the mixing ratio of all hydrometeor species. By contrast, in the double-moment scheme, the intercept can be varied with an additional prediction of the total number concentration. Generally, double-moment schemes, which have more freedom to represent hydrometeors' particle size distribution, outperform single-moment schemes in representing the convective structure and stratiform coverage (Morrison et al. 2009; Dawson et al. 2010; Putnam et al. 2017a). Nevertheless, the spread characteristics of convective-scale ensemble forecasts using variable initial conditions and fixed microphysics schemes and how the double-moment and single-moment schemes affect the representation of forecast uncertainty has not yet been investigated.
This study aims to investigate the sensitivity of the ensemble-estimated forecast uncertainty associated with severe convection to selected microphysics schemes. The selection of microphysics schemes in an ensemble is crucial but usually is overlooked in studies. In addition, it is particularly of interest to investigate whether the use of double-moment schemes that have more degrees of freedom than single-moment schemes can alleviate the underdispersive issue. An extreme precipitation event that occurred over southwestern Taiwan on 15-16 June 2008 is selected. This event has been regarded as a complex and long-lived precipitation system that is challenging to simulate (Xu et al. 2012, Yang et al. 2014, Chang et al. 2015). The results of one case study help to inform the selection of microphysics schemes in either ensemble prediction or ensemble-based data assimilation systems. The remainder of this paper is organized as follows: section 2 provides an overview of the case study and the design of the experiment, including the analysis ensemble, the Weather Research and Forecasting (WRF) Model configuration, microphysics schemes selected, and the analysis methods. Section 3 presents the forecast uncertainty results for each microphysics scheme and their intrinsic characteristics in deterministic forecasts. Finally, section 4 provides a summary and discussion of the study.

\section{Experimental design}

\section{a. Overview of the precipitation system on 15-16 June 2008}

This study simulates an extreme rainfall event caused by a long-lived mesoscale convective system during the Southwest Monsoon Experiment/Terrain-Influenced Monsoon Rainfall Experiment (SoWMEX/TiMREX) intensive observation period 8 (Jou et al. 2011). This event was affected by a multiscale interaction, including the mei-yu frontal system in Northern Taiwan and active convection caused by the steady southwesterly flow with abundant water vapor. Several studies have documented the environmental conditions and mechanisms of this heavy rainfall event (Xu et al. 2012; Davis and Lee 2012; Tu et al. 2014). This subsection provides a brief review.

At 0000 UTC 13 June 2008 (3 days before the analysis of NWP forecasts), a cyclone at $850-\mathrm{hPa}$ and accompanied by a trough at $500-\mathrm{hPa}$ located in southwestern China induced a strong low- to midlevel southwesterly flow, which contributed to the formation of the mei-yu frontal system near Taiwan on 14 June. This strong flow transported abundant water vapor to southwestern Taiwan; after arriving inland, the flow became southerly owing to the surface friction and topography of Taiwan, which gave rise to low-level convergence over the coastal region. These conditions aided the development of a convective system on 14 and 15 June. This precipitation period left a broad cold pool (temperature depression of $2^{\circ}-4^{\circ} \mathrm{C}$ ) over the coastal area. The convection over southwestern Taiwan stopped on 15 June, but later, the remnant cold pool outflow further enhanced the low-level convergence. This cold pool acted as an extended orographic barrier to the 
(a) 061513UTC

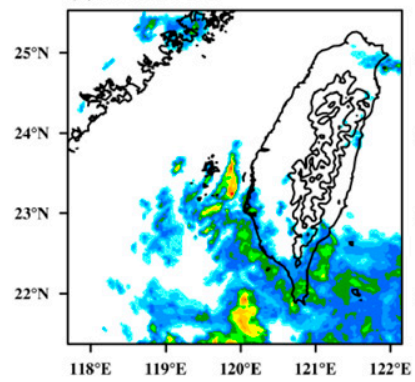

(e) $061601 \mathrm{UTC}$

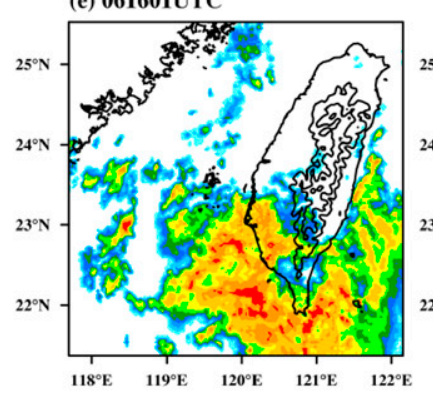

(b) 061516UTC

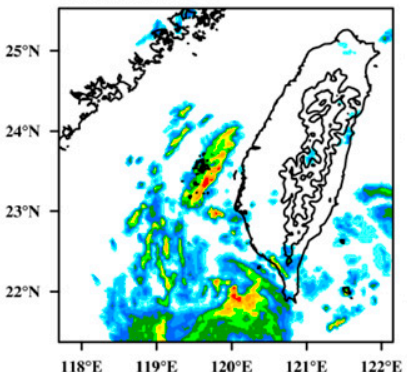

(f) 061604UTC

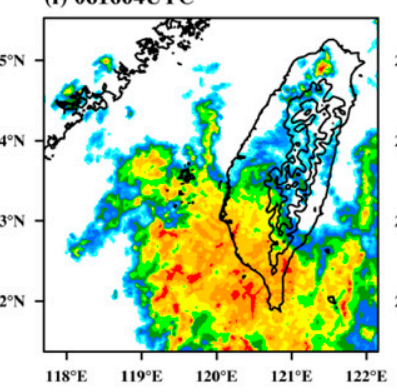

(c) 061519UTC

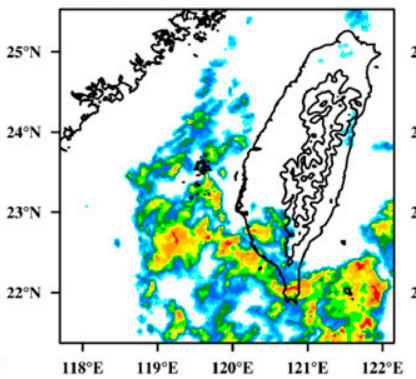

(g) 061607UTC

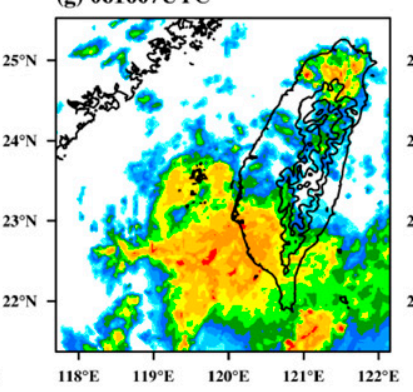

(d) $061522 \mathrm{UTC}$

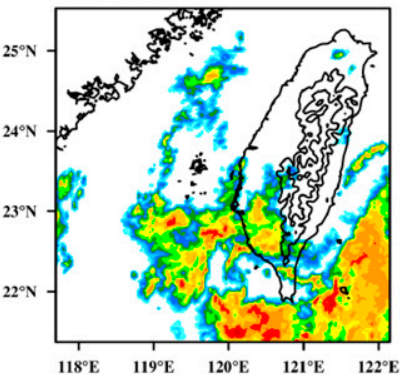

(h) 061610UTC

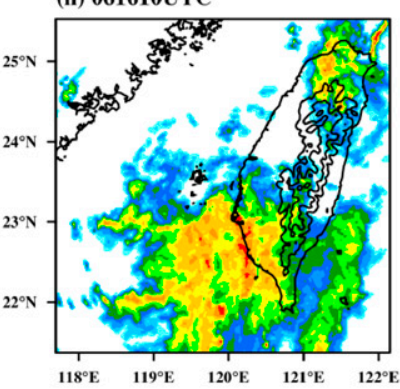

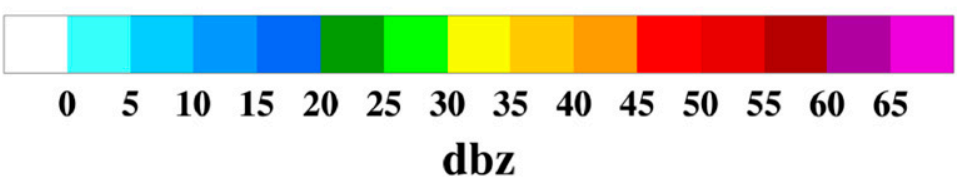

FIG. 1. Composite maximum combined radar reflectivity $(\mathrm{dBZ})$ from quantitative precipitation estimation and segregation using multiple sensors from (a) 1300 UTC 15 Jun to (h) 1000 UTC 16 Jun 2008.

moist southwesterly flow, triggering new convection upstream along the cold pool boundary (the coastal region of southwestern Taiwan; Xu et al. 2012). Offshore flow related to land-sea-breeze circulation at night also enhanced and maintained the convergence zone near southwestern Taiwan (Tu et al. 2014). These factors led to a long-lived mesoscale convective system, which resulted in an extended period of heavy precipitation on 16 June.

Figure 1 illustrates the development of the weather system on 15-16 June 2008 through the mosaic column-maximum radar reflectivity (combining the maximum reflectivity at each column into a single 2D diagram) from quantitative precipitation estimation and segregation using multiple sensors (Gourley et al. 2002; Chang et al. 2009). At 1600 UTC 15 June 2008, fragmented convection gathered and developed into an offshore southeast-northwest-oriented convective system. This convection gradually moved northwest; it reached the coastal region of southwestern Taiwan by 1900 UTC and then formed a complex mesoscale convective system that lasted nearly 18 h. According to rain gauge data collected over southwestern Taiwan, precipitation began at 1500 UTC 15 June 2008 and lasted for $24 \mathrm{~h}$ (Fig. 2, bottom); more than $300 \mathrm{~mm}$ of rain fell on the coastal region (Fig. 2, top).

\section{b. Ensemble initializations}

To reduce the spinup time and address the initial condition uncertainty from mesoscale dynamical instabilities, the initial conditions used to create the 36-member ensemble forecast are taken from Yang et al. (2014) and are valid at 1200 UTC 15 June 2008. The analysis ensemble is generated by launching 36 ensemble forecasts commencing at 1800 UTC 11 June with a random perturbation based on the 3DVar background error covariance (Sun et al. 2016) centered on the NCEP GFS Final Analysis (FNL $1^{\circ} \times 1^{\circ}$ data). After $30 \mathrm{~h}$ of forecasting, the assimilation period starts from 0000 UTC 13 June and lasts until 1200 UTC 15 June with 6-h intervals. The data assimilation procedure based on the WRF-local ensemble transform Kalman filter (WRF-LETKF; Yang et al. 2014) system is applied at the outermost domain (27-km grid spacing). Observations include the assimilation of the conventional meteorological data, satellite wind vectors, and COSMIC GPS-radio occultation bending angles.

Yang et al. (2014) performed WRF-LETKF analyses and showed that the results could capture moisture transport from the South China Sea toward Taiwan and the convergence zone offshore of southwestern Taiwan better than the global analysis. Moreover, the forecasts initialized after 1200 UTC 15 June indicated considerable progress in predicting the heavy rainfall during the event of interest (Yang et al. 2014).

\section{c. Model configuration}

This study employs WRF model version 3.7.1 (Skamarock and Klemp 2008) for all experiments. The 36-member ensemble forecasts were warm-started and initialized by downscaling 

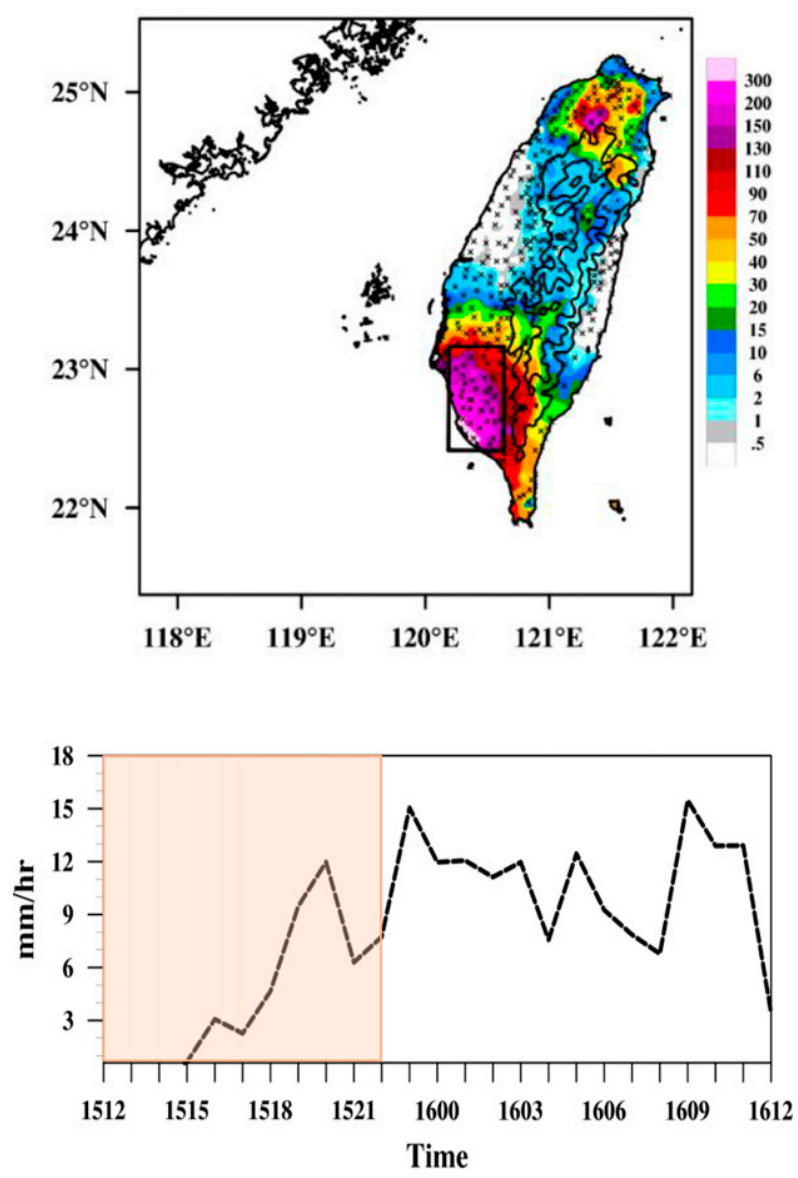

FIG. 2. (top) 24-h accumulated rainfall (mm) from 1200 UTC 15 Jun to 1200 UTC 16 Jun 2008. The black dots denote available rain gauges. (bottom) Time series of average hourly rainfall $\left(\mathrm{mm} \mathrm{h}^{-1}\right)$ from the rain gauges in the black rectangular box in the top panel. The orange-shaded box represents the period of time (1200-2200 UTC 15 Jun) analyzed in this study.

each WRF-LETKF analysis member from $27-\mathrm{km}$ grid spacing to 9 - and $3-\mathrm{km}$ grid spacing to resolve the convection details more clearly. Figure 3 displays the model domain, which is constructed from three nested domains with $181 \times 151,161 \times$ 151 , and $151 \times 151$ grid points. The innermost domain is arranged to cover southwestern Taiwan and the adjacent ocean area. Each domain has 52 vertical levels up to $50 \mathrm{hPa}$ and the same physical parameterization, including the Rapid Radiative Transfer Model longwave scheme (Mlawer et al. 1997), Dudhia shortwave scheme (Dudhia 1989), Yonsei University planetary boundary scheme (Hong et al. 2006), and Grell-Freitas cumulus scheme (Grell and Freitas 2014). The cumulus scheme is applied in domains 1 and 2 only.

Four sets of ensemble forecasts that adopted different microphysics schemes (discussed in the subsequent section) under the same analysis ensemble are initialized from 1200 UTC 15 June 2008 and finished at 1200 UTC 16 June with a 10 -s time step in the innermost domain. The lateral boundary conditions for the outer domain (d01) are obtained from the

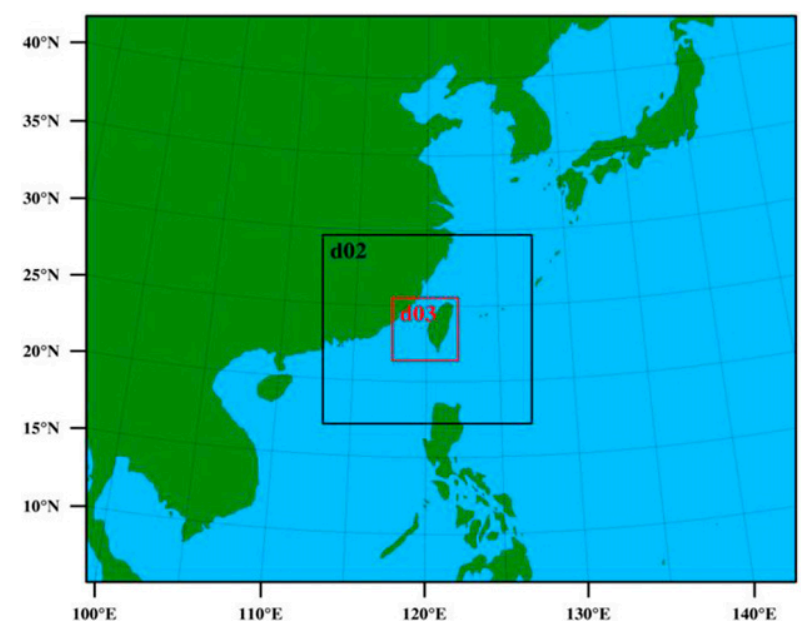

FIG. 3. Three nested domains of WRF Model design. The horizontal grid spacing is 27,9 , and $3 \mathrm{~km}$ in $\mathrm{d} 01-03$, respectively.

NCEP GFS FNL $1^{\circ} \times 1^{\circ}$ data at a 6 -h interval for 1200 UTC 15 June to 1800 UTC 16 June.

\section{d. Description of microphysics schemes}

Four bulk microphysics schemes are selected to investigate the ensemble spread structure: the Goddard Cumulus Ensemble (GCE; Tao et al. 2003), Morrison (MOR; Morrison et al. 2005), WRF single-moment 6-class (WSM6; Hong and Lim 2006), and WRF double-moment 6-class (WDM6; Lim and Hong 2010) schemes. The WRF-release version of these schemes is three-ice, containing graupel-like rimed ice and unrimed ice, including cloud ice and snow. Additionally, all particles are parameterized using a gamma distribution function of the following form:

$$
N_{x}(D)=N_{0 x} D^{\mu_{x}} e^{-\lambda_{x} D},
$$

where $x=c, r, s, g, i$ corresponds to five hydrometeor categories: cloud water, rain, snow, graupel, and cloud ice, respectively; $N_{x}$ denotes the number concentration; $D$ denotes the particle diameter; and $N_{0 x}, \lambda_{x}$, and $\mu_{x}$ are the intercept, slope, and shape parameters that determine the degree of freedom of the particle size distribution curve, respectively. Generally, single-moment and double-moment schemes have $\mu_{x}=0$, which leads to inverse-exponential curve forms. The slope and intercept parameters are formulated as functions of the number concentration $N_{x}$ and mixing ratio $q_{x}$. In singlemoment schemes, $N_{x}$ is specified given fixed $N_{0 x}$ and, together with the predicted $q_{x}$, enables control of the slope parameter. In the double-moment schemes, $N_{x}$ and $q_{x}$ are both prognostic; therefore, the slope and intercept parameters can be handled with flexibility.

GCE is a single-moment scheme that follows the parameterization of Lin et al. (1983) but has a more appropriate saturation adjustment scheme (Tao et al. 1989) for addressing the issue of supersaturation. This scheme is currently used operationally by the Central Weather Bureau of Taiwan; thus, its performance is of particular interest in this study. WSM6 and 
WDM6 are also based on the parameterization of Lin et al. (1983) and have similar parameterization for cold-phase hydrometeors; these are handled in the single-moment approach but $N_{0 s}$ is allowed to vary with temperature. WSM6 and WDM6 differ in that WDM6 has three additional prognostic variables: cloud condensation nuclei and the number concentrations of cloud and rain. Therefore, WDM6 can be viewed as a partial double-moment scheme; its ice-phase categories belong to a single-moment scheme, whereas the warm rain species belong to a double-moment scheme. Additionally, WDM6 has $\mu_{r}=1$, which differs from other schemes. Selecting WSM6 and WDM6 enabled the examination of the double-moment effects on the structure and magnitude of the ensemble spread. MOR is a complete double-moment scheme that predicts $N_{x}$ for both warmand cold-phase hydrometeors. The inclusion of MOR allows us to examine whether the effectiveness of capturing forecast uncertainty is related to the complexity of the microphysics scheme.

\section{e. Evaluation of the forecast uncertainty}

In an ensemble forecast system, the ensemble spread plays a vital role in estimating the forecast uncertainty. Considering a scalar example where the forecast error at a specific time can be represented as

$$
\varepsilon_{b}=x_{b}-x_{t}=M\left[\varepsilon_{b 0}\right]+\varepsilon_{M},
$$

where the background forecast error $\left(\varepsilon_{b}\right.$ is the difference between the model state $\left(x_{b}\right)$ and the actual atmosphere state $\left(x_{t}\right)$, and it can also be viewed as the sum of the accumulated initial condition error $\varepsilon_{b 0}$ and model error $\varepsilon_{M}$. The operator $M$ denotes the forecast model. Moreover, the forecast error variance is

$$
\sigma_{b}^{2}=E\left[\varepsilon_{b}^{2}\right]=E\left[\left(x_{b}-x_{t}\right)^{2}\right],
$$

where $E$ represent the expected value, i.e., the average after performing many similar realizations. However, given that the true value of the state variable is unknown, and observations may not be available in the entire space and time for real case, it is often assumed that the ensemble mean approaches the actual state and exploit the limited ensemble members to estimate the expected amplitude of forecast error (forecast error variance) as

$$
\sigma_{b}^{2} \approx \frac{1}{M-1} \sum_{m=1}^{M}\left(x_{b}^{m}-\bar{x}_{b}\right)^{2}
$$

where $M$ is the ensemble size and $\bar{x}_{b}$ is the ensemble-mean value of the model state. Although the ensemble estimated variance is algebraically tractable, the standard deviation $\sigma_{b}$ has the advantage of being expressed in the same unit as the state variable itself, often used to represent the ensemble spread among ensemble members (Ştefănescu et al. 2006; Chung et al. 2013).

In this study, we mainly evaluate the conditional sensitivity of the standard deviation of different state variables to the same initial perturbations, where the conditioning is on each of four microphysical schemes: $\left(\partial \sigma_{b} / \partial x_{b 0}\right)\left|\mathrm{GCE}, \quad\left(\partial \sigma_{b} / \partial x_{b 0}\right)\right| \mathrm{MOR}$, $\left(\partial \sigma_{b} / \partial x_{b 0}\right)\left|\mathrm{WSM},\left(\partial \sigma_{b} / \partial x_{b 0}\right)\right| \mathrm{WDM}$. Because $x_{b 0}$ is fixed for all experiments, we can directly compare the difference in $\sigma_{b}$ to evaluate the characteristics of the forecast uncertainty of the ensemble that adopts different microphysics schemes.

Furthermore, the RMDTE (Melhauser and Zhang 2012; Nielsen and Schumacher 2016) is employed to quantify the ensemble spread associated with dynamic and thermodynamic fields. RMDTE is a modified version of the difference total energy (DTE) $\quad\left(\mathrm{DTE}=(1 / 2) \sum_{i, j, k, m}\left[U_{i, j, k, m}^{\prime 2}+V_{i, j, k, m}^{\prime 2}+\right.\right.$ $\left.\left(C_{p} / T_{r}\right) T_{i, j, k, m}^{\prime 2}\right]$, where $U^{\prime}, V^{\prime}$, and $T^{\prime}$ are calculated from the difference between ensemble members and the ensemble mean in the zonal wind, meridional wind, and temperature; $C_{p}$ is the heat capacity of dry air; and $T_{r}=287 \mathrm{~K}$ is a reference temperature; Zhang et al. 2003) and is defined as

$$
\operatorname{RMDTE}_{i, j, t}=\sqrt{\frac{1}{M} \sum_{m=1}^{M} \sum_{k=0}^{K} \frac{p(k+1)-p(k)}{p(K)-p(0)} \frac{1}{2}\left[\left(U_{i, j, k, m}^{\prime}\right)^{2}+\left(V_{i, j, k, m}^{\prime}\right)^{2}+\frac{C_{p}}{T_{r}}\left(T_{i, j, k, m}^{\prime}\right)^{2}\right]},
$$

where $K$ is the number of vertical levels, and $p(k)$ is the pressure on level $k$. The main difference between the DTE and RMDTE is that the latter takes the pressure-weighted average along the vertical level.
A more detailed analysis of the spatial-scale interaction of the error growth can be obtained from the spectra of the RMDTE. For a given 2D field $x_{i, j}$, the 2D discrete Fourier transform is defined as

$$
X_{p, q}=\frac{1}{N_{i} \Delta N_{j}} \sum_{j=0}^{N_{j}} \sum_{i=0}^{N_{i}} x_{i, j} \Delta \exp \left[-\sqrt{-1} \Delta\left(\frac{2 \pi p i}{N_{i}}+\frac{2 \pi q j}{N_{j}}\right)\right] ; \quad p=0, \ldots, N_{i} ; \quad q=0, \ldots, N_{j},
$$

where $N_{i}$ and $N_{j}$ are the numbers of original grids in the $x$ and $y$ directions, respectively, and $X_{p, q}$ is the spatial frequency domain with $p$ and $q$ denoting the discrete sample index. The discrete samples of $p$ and $q$ in the transformed domain 
(a) GCE 1900

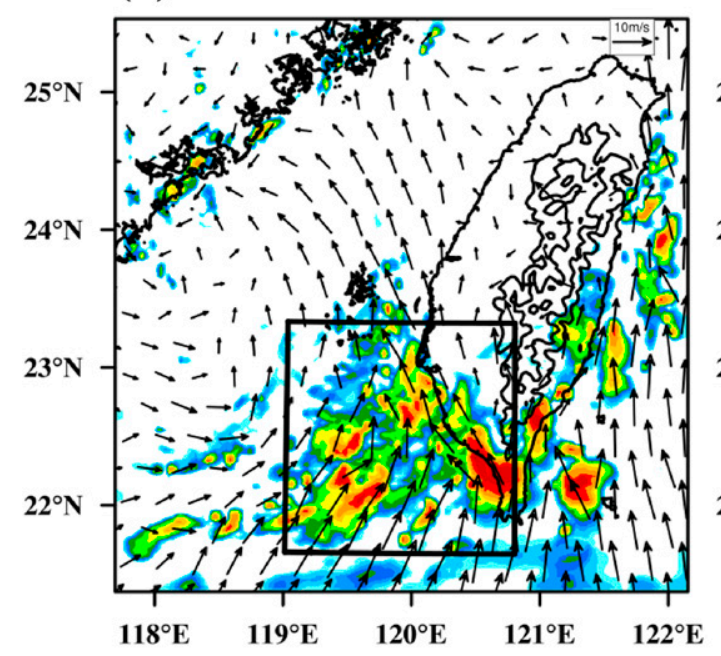

(c) WSM6 1900

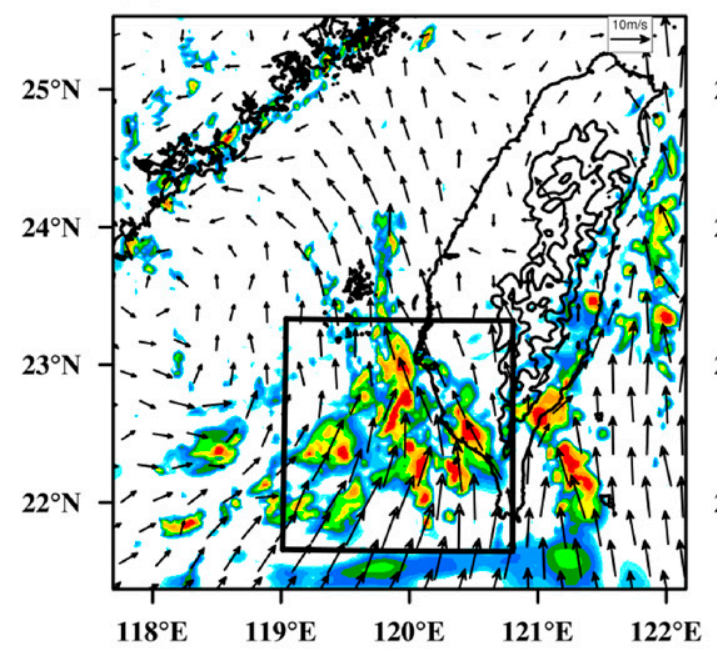

(b) MOR 1900

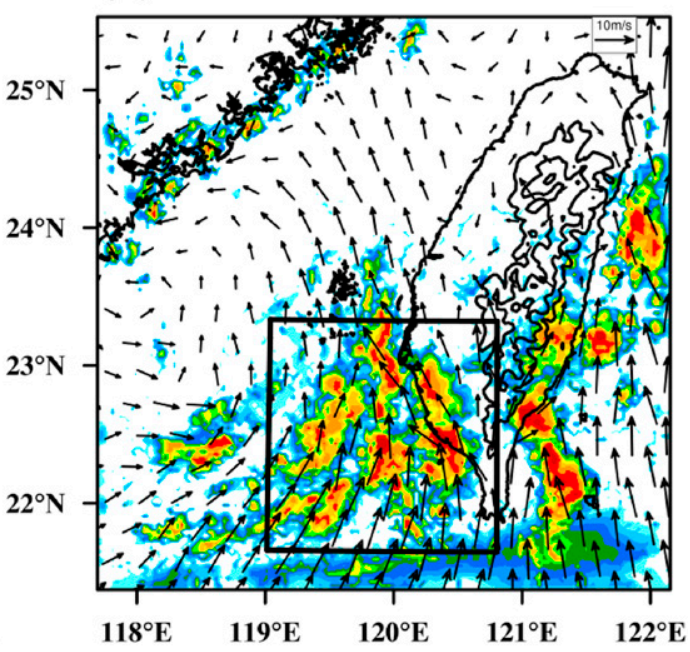

(d) WDM6 1900

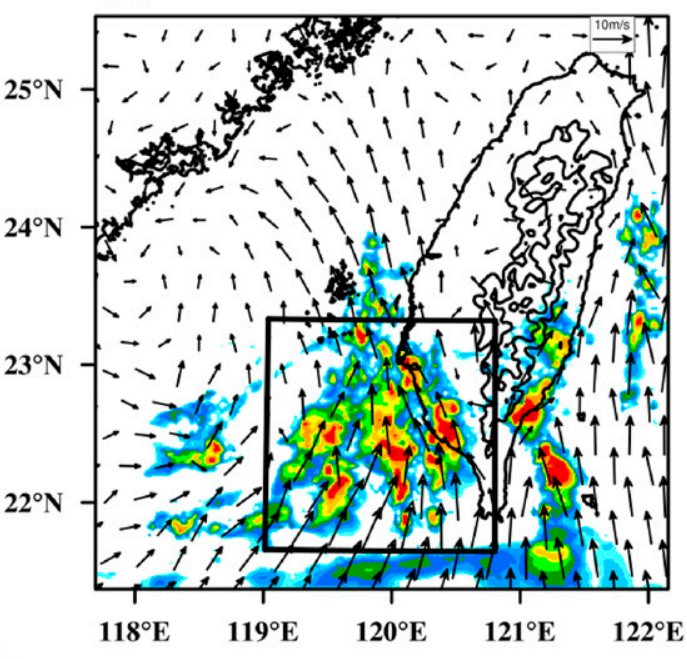

dbz

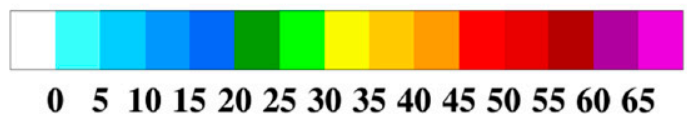

FIG. 4. Column-maximum model-derived radar reflectivity $(\mathrm{dB} Z)$ with black arrows representing the $10-\mathrm{m}$ wind field at 1900 UTC 15 Jun 2008, as simulated using the (a) GCE, (b) MOR, (c) WSM6, and (d) WDM6 schemes. Black contours on land indicate the topographic elevation from 1 to $3 \mathrm{~km}$. The black square line indicates the region to be evaluated in the subsequent analyses.

represent the spatial frequency values of $2 \pi p / L_{x}$ and $2 \pi q / L_{y}$, respectively, where $L_{x}$, and $L_{y}$ are the length of the original domain in the $x$ and $y$ directions, respectively. Additionally, we apply the 2D detrending methods described by Errico (1985) to remove unresolved global scales and prevent alias problems. Finally, to determine the spectrum in 1D $(k)$ space, the circular truncation method is applied to the 2D $X_{p, q}$ [Eq. (5) in Errico 1985].

\section{Results}

The present analysis focuses on the first 10-h short-term forecast (1200-2200 UTC 15 June 2008) because this period exhibits critical features that leads to the development of the long-lived mesoscale convective system. First, the deterministic forecasts are examined to overview the model simulation and general characteristics of the four microphysics schemes. 
(a) GCE

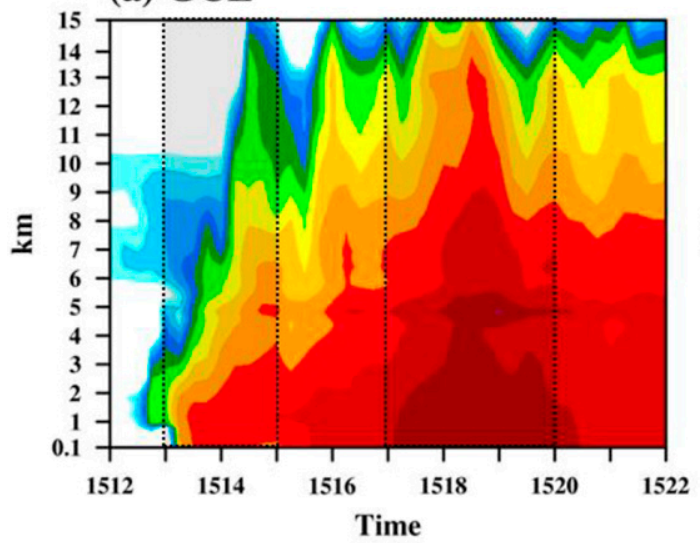

(c) WSM6

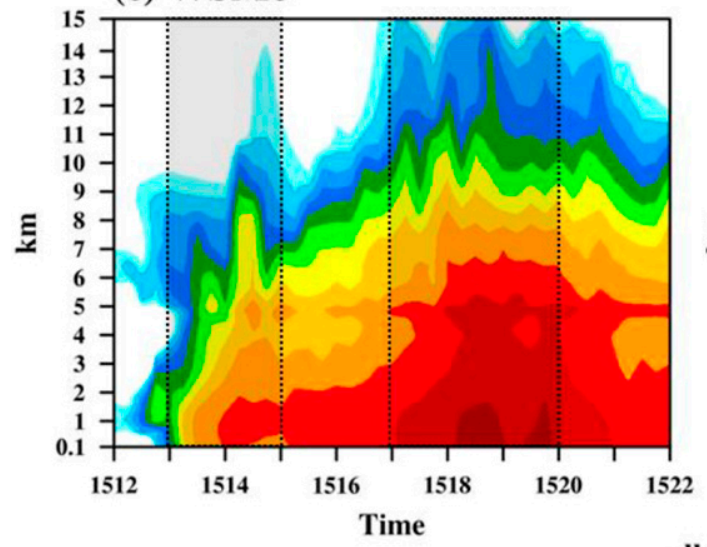

(b) MOR

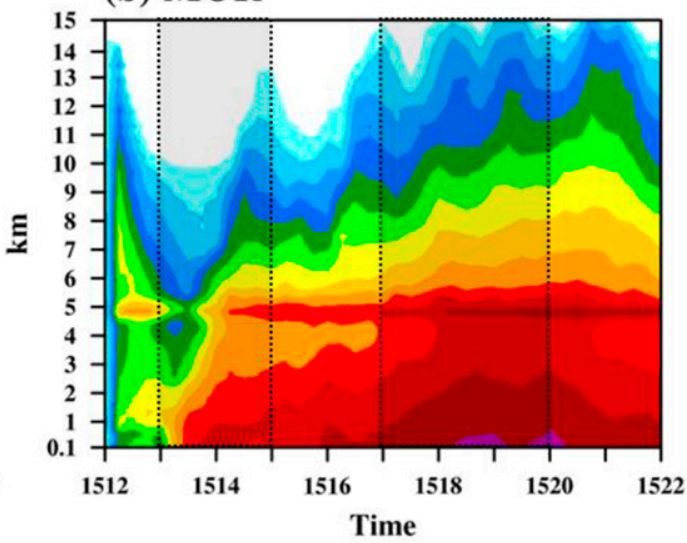

(d) WDM6

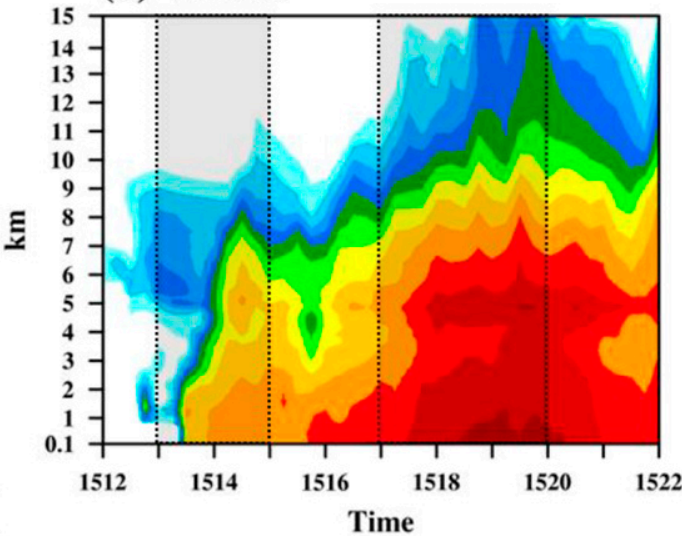

dbz

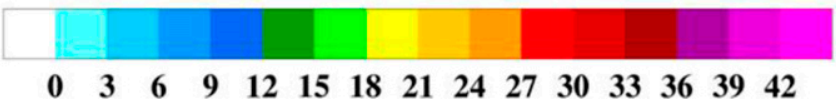

FIG. 5. Time-height cross section of model-derived radar reflectivity (dBZ) averaged over the black box illustrated in Fig. 4 for the (a) GCE, (b) MOR, (c) WSM6, and (d) WDM6 schemes. The black-shaded areas highlight the two fast-error-growth periods (1300-1500 and 1700-2000 UTC) of the simulation.

The amplitude and structure of the forecast uncertainties in different state variables are then illustrated using four sets of fixed-microphysics ensemble forecasts under the same initial conditions.

\section{a. Deterministic forecast: General features of each microphysics scheme}

Figure 4 presents the column-maximum radar reflectivity and 10-m horizontal wind fields simulated for 1900 UTC. In all experiments, a clear convective system over southwestern Taiwan is forecast, similar to the observation (Figs. 1c,d), with the precipitating system associated with the strong southwesterly flow mainly concentrated in coastal areas. In such a wind pattern, moist air is advected from the ocean toward the island; when moving inland, the wind is deflected due to surface friction and orography, resulting in convergence and enhancing the convective activity.
To better understand the convective structure and temporal evolution of this heavy rainfall event for the investigated schemes, time-height diagrams of the horizontally averaged radar reflectivity (black box in Fig. 4) are displayed in Fig. 5. All experiments indicate a precipitation system that reaches its peak magnitude during 1800-2000 UTC, and the melting layer, corresponding to a brightband signature, is located near $5 \mathrm{~km}$ AGL. GCE results in the highest vertical development with reflectivity $>30 \mathrm{dBZ}$ observed up to $10 \mathrm{~km}$ AGL (Fig. 5a). By contrast, MOR results in the shallowest convection but produces the largest reflectivity near the surface (Fig. 5b). Figures 5c,d show a similar convection structure between WSM6 and WDM6, but the latter presents a more notable brightband signature near the melting layer $(5 \mathrm{~km})$, consistent with the findings of Lim and Hong (2010) and Duda et al. (2014).

In an attempt to distinguish the microphysical differences among the microphysics schemes in the various convective 
(a) GCE 1900

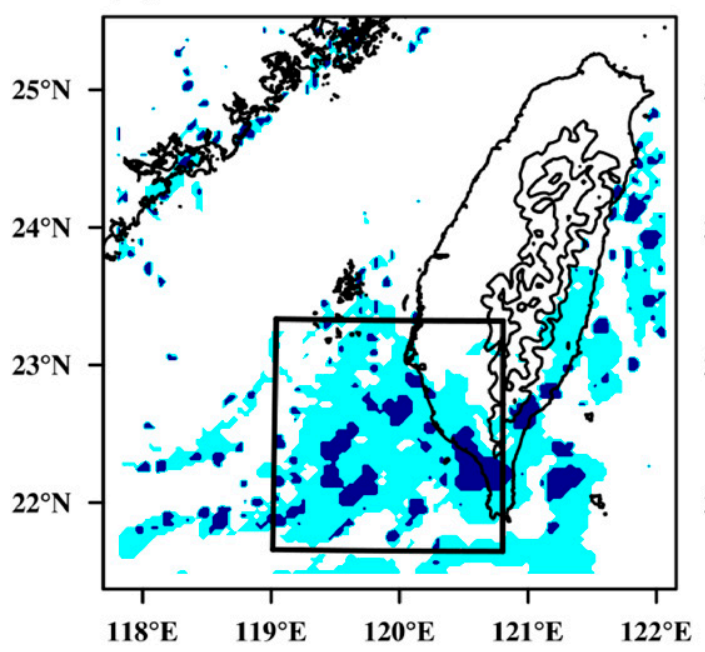

(c) WSM6 1900

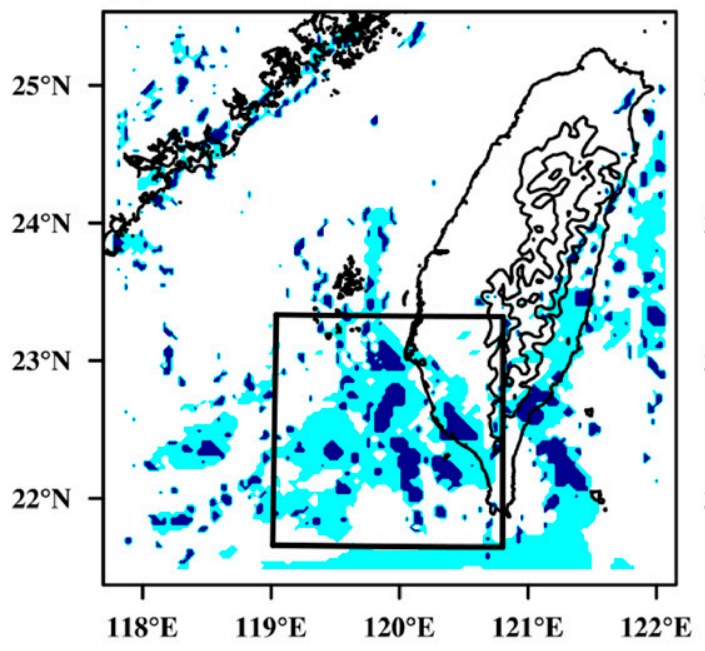

(b) MOR 1900

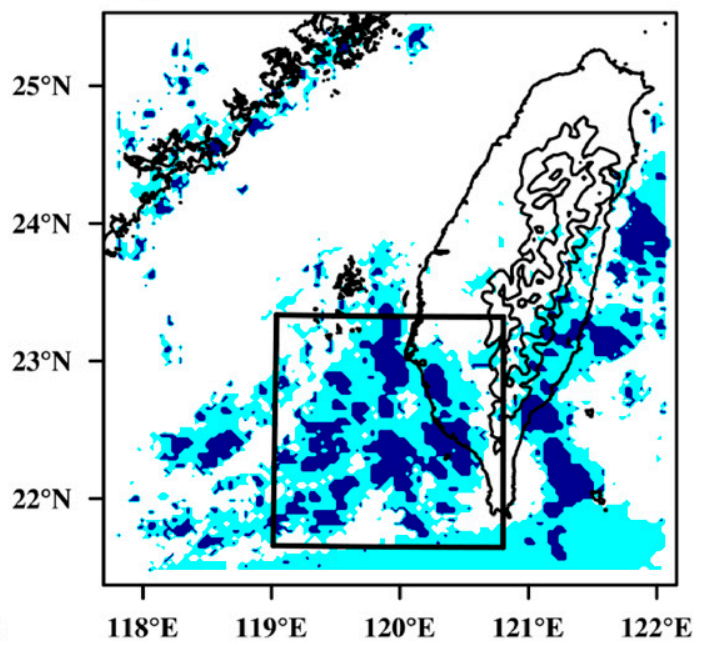

(d) WDM6 1900

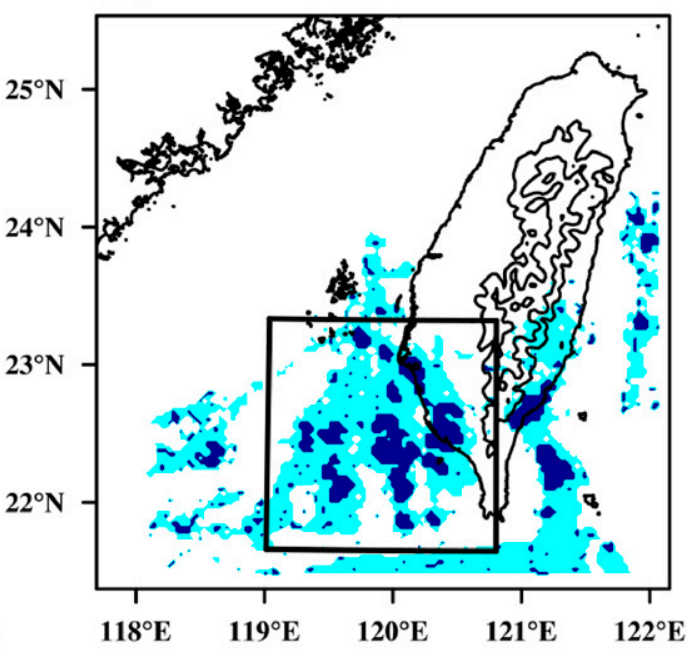

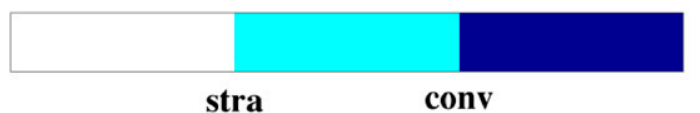

FIG. 6. Separation of the mesoscale convective system area into convective (deep blue) and stratiform (light blue) regions using the approach of Steiner et al. (1995) with the convective criteria set on $41 \mathrm{dBZ}$ for the (a) GCE, (b) MOR, (c) WSM6, and (d) WDM6 schemes.

development stages, the precipitation system is separated into convective and stratiform areas by using the algorithm proposed by Steiner et al. (1995). Any point with reflectivity that exceeds $41 \mathrm{dBZ}$ is designated part of a convective core; grid points surrounding the core are also made convective. Figure 6 presents the partition results for the four microphysics schemes at 1900 UTC. The stratiform distributions (overall rainfall area) of these microphysics schemes are similar, but their convective areas have distinct features. GCE has a large convective portion near Southern Taiwan (Fig. 6a); that for MOR is the largest (Fig. 6b); and that for WDM6 contains more and larger convective cores than that for WSM6 (Figs. 6c,d).

Based on the partition results, Fig. 7 shows the vertical profile of the horizontally (black box in Fig. 4) and temporally (1600-2200 UTC) averaged mixing ratio of rainwater $\left(q_{r}\right)$, cloud water $\left(q_{c}\right)$, graupel $\left(q_{g}\right)$, snow $\left(q_{s}\right)$, and cloud ice $\left(q_{i}\right)$ over the grid points that are designated as convection (Figs. $7 \mathrm{a}-\mathrm{e}$ ) or stratiform (Figs. $7 \mathrm{f}-\mathrm{j}$ ). All simulations demonstrate a pronounced difference in the amount and distribution of these hydrometeors. For example, the quantity of hydrometeors is almost 10 times larger in the convective region. A 


\section{Convective region}

(a) $\mathrm{qr}$

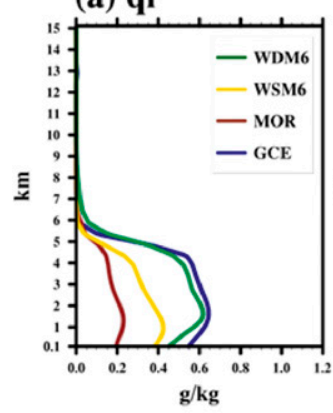

(b) qc

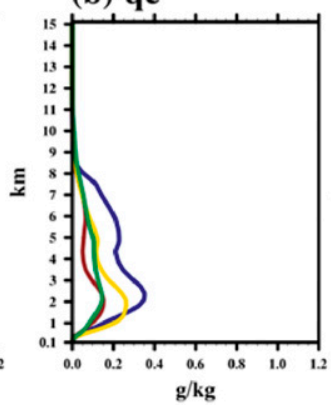

(c) $\mathrm{qg}$

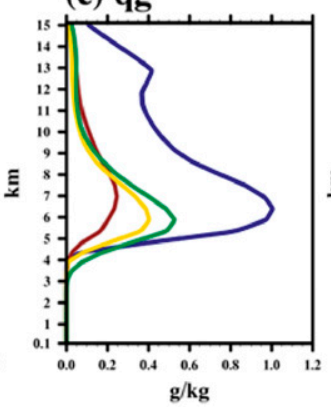

(d) qs

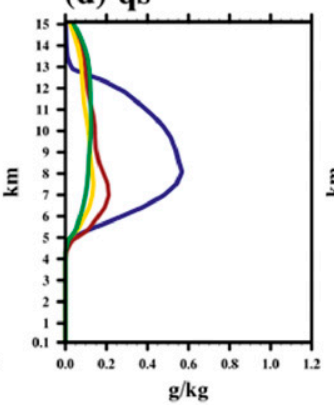

(e) qi

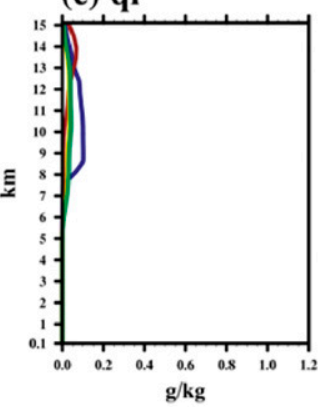

\section{Stratiform region}

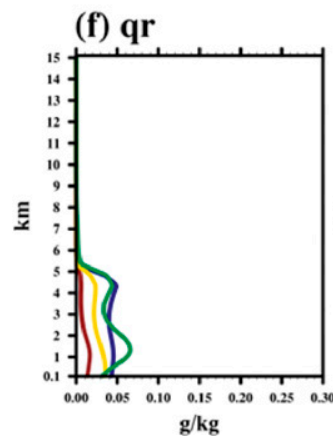

(g) qc

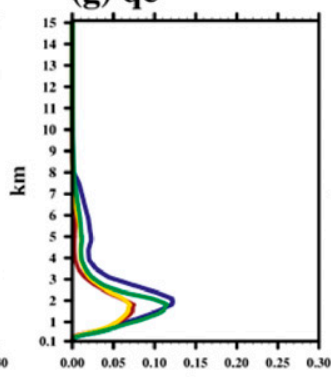

$\mathrm{g} / \mathbf{k g}$ (h) qg

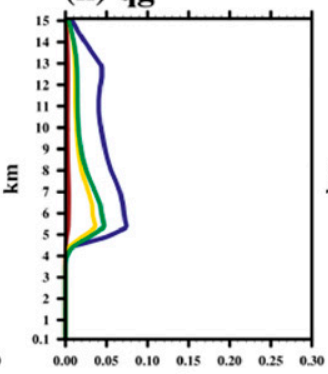

$\mathrm{g} / \mathrm{kg}$ (i) $\mathrm{qs}$

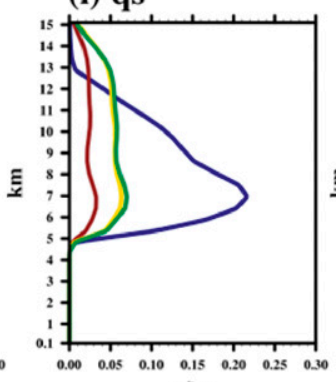

$\mathrm{g} / \mathrm{kg}$

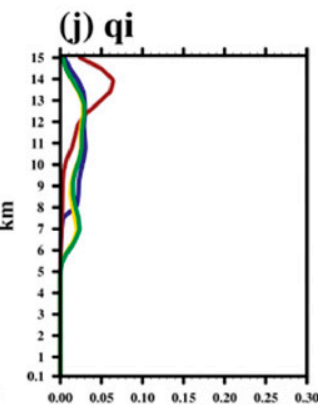

$\mathrm{g} / \mathrm{kg}$

FIG. 7. Vertical profile of space (black box in Fig. 4) and time (1600-2200 UTC) averaged hydrometeors for (left to right) rainwater, cloud water, graupel, snow, and ice mixing ratio $\left(\mathrm{g} \mathrm{kg}^{-1}\right)$ for (a)-(e) convective regions and (f)-(j) for stratiform regions. Blue for GCE, red for MOR, yellow for WSM6, and green for WDM6.

higher $q_{c}$ distribution characterizes the convective area, and $q_{g}$ dominates the melting layer. Conversely, $q_{c}$ in the stratiform area is concentrated at $2 \mathrm{~km} \mathrm{AGL}$, and $q_{s}$ dominates among the ice-phase categories.

GCE generally exhibits more hydrometeors than do other schemes. In GCE, $q_{g}$ and $q_{s}$ are mainly several times higher than those in other schemes (blue line in Figs. 7c,d,h,i), which explains the most active reflectivity feature for this scheme (Fig. 5). Also, the vertical structure of $q_{s}$ and $q_{g}$ is different from that in other schemes; $q_{g}$ has two peaks at 6.5 and $13 \mathrm{~km}$ AGL, and $q_{s}$ is limited to lower than $13 \mathrm{~km}$ AGL. In contrast to GCE, MOR obtains the lowest mixing ratios of every hydrometeor, the exception being $q_{i}$, which is the largest at altitudes higher than $13 \mathrm{~km}$ AGL (red line in Figs. 7e,j). Although MOR results in the smallest $q_{r}$ in the convective region (Fig. 7a), its radar reflectivity is the largest near the surface (Fig. 5b). The main reason for this is that MOR produces the lowest intercept parameter, resulting in a much broader rain size distribution (not shown), leading to strong reflectivity (Putnam et al. 2017a). WSM6 and WDM6 obtain almost the same distribution of ice-phase species regardless of stratiform and convection regions (yellow and green lines in Figs. $7 \mathrm{c}-\mathrm{e}, \mathrm{h}-\mathrm{j}$ ) because of the similar treatment of frozen hydrometeor processes in these schemes. A major difference between WSM6 and WDM6 is in the $q_{r}$ profile; WDM6 results in a much larger $q_{r}$, especially in the convective area (Fig. 7a).

To further understand the intrinsic differences among the microphysics schemes, their microphysical tendencies are analyzed. These heating-cooling characteristics caused by the phase changes of water are crucial for providing the energy source for the convective system, thus modifying the vertical temperature structure. Diabatic heating-cooling processes lead to significant variability when various microphysics schemes are adopted (Gilmore et al. 2004; Morrison et al. 2009; Morrison and Milbrandt 2011; Dawson et al. 2010). Figure 8 shows the diabatic heating-cooling processes at varying heights in the different microphysics schemes; the figures are obtained by averaging the tendencies at each grid pixel in the convective or stratiform region shown in Fig. 6-that is,

$$
\Delta T_{m p, k}=\frac{1}{N} \sum_{i, j, t}\left(L_{v, s, f} / C_{p}\right) \Delta \Delta q_{i, j, k, t},
$$

where $\Delta T_{m p, k}$ represents the space $(i, j)$ and time $(t)$ averaged tendencies resulted from microphysical processes at each model layer $(k) ; L_{v, s, f}$ is the latent heat constant for vaporization, sublimation, and fusion, respectively; $C_{p}$ is the specific heat capacity; $\Delta q$ is the rate of change of a specific 


\section{Convective region}

(a) GCE

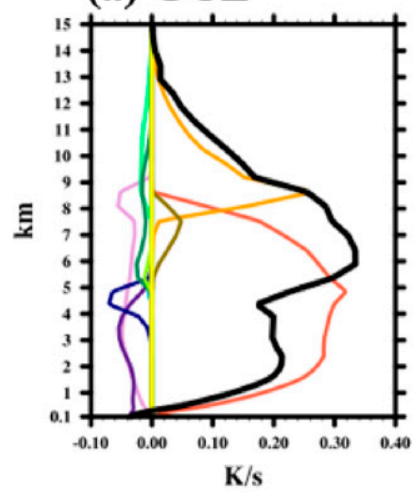

(b) MOR

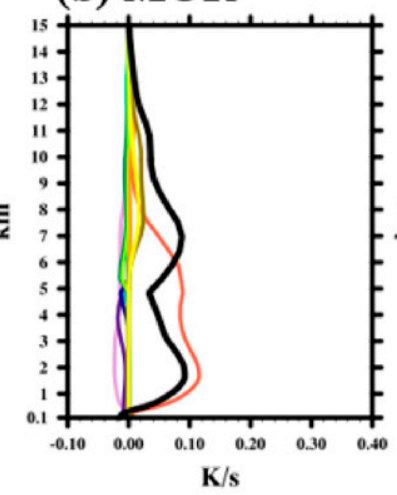

(c) WSM

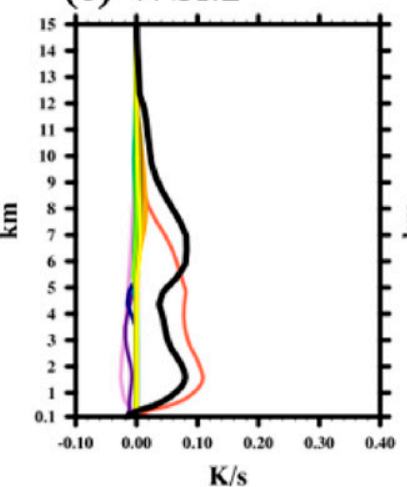

(d) WDM

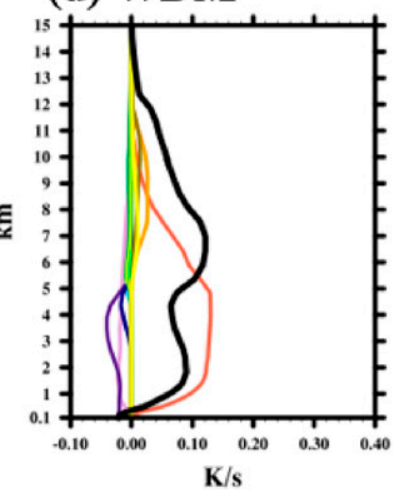

Stratiform region

(e) GCE

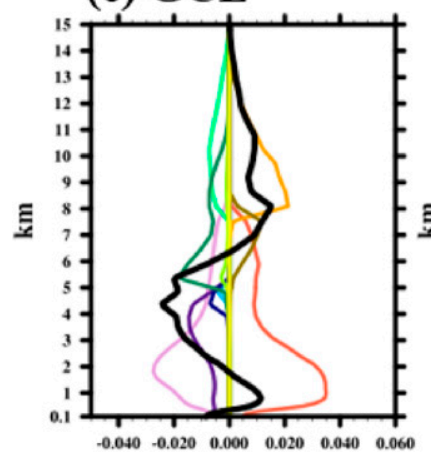

$\mathrm{K} / \mathrm{s}$ (f) MOR

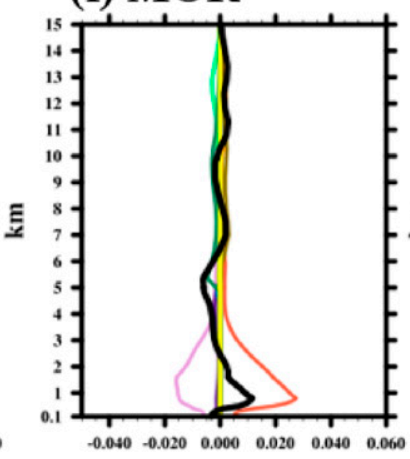

$\mathrm{K} / \mathrm{s}$ (g) WSM

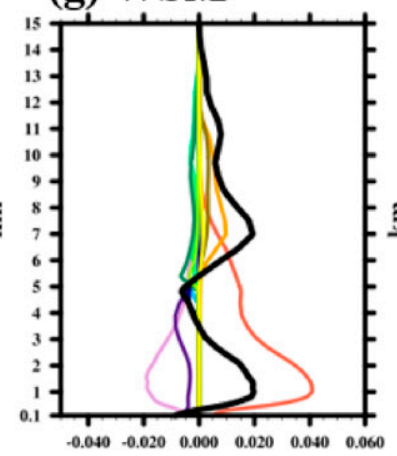

$\mathrm{K} / \mathrm{s}$ (h) WDM

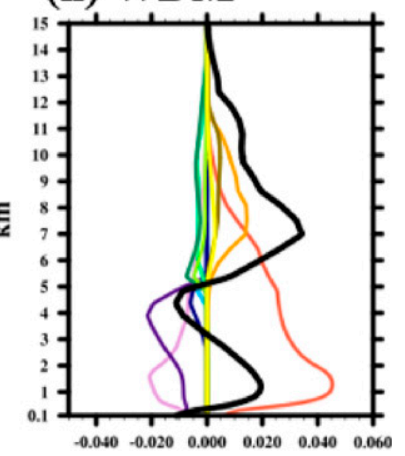

$\mathrm{K} / \mathrm{s}$
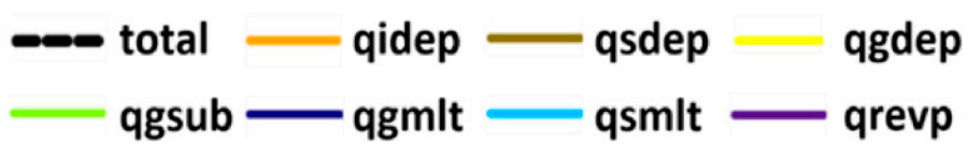

qisub

qssub

qcevp

qccon

FIG. 8. Vertical profile of space (black box in Fig. 4) and time (1600-2200 UTC) averaged microphysical process tendencies (K s ${ }^{-1}$ ): condensation of cloud water (qccon); evaporation of cloud water (qcevp) and rainwater (qrevp); melting of graupel (qgmlt) and snow (qsmlt); sublimation of graupel (qgsub), snow (qssub), and cloud ice (qicub); and deposition of graupel (qgdep), snow (qsdep), and cloud ice (qidep) for the (a) GCE, (b) MOR, (c) WSM6, and (d) WDM6 schemes in convective regions and (e) GCE, (f) MOR, (g) WSM6, and (h) WDM6 schemes in stratiform regions. The tendencies are calculated by multiplying the change rate $\left(\mathrm{kg} \mathrm{kg}^{-1} \mathrm{~s}^{-1}\right)$ by the heat of evaporation (or fusion; $\mathrm{J} \mathrm{kg}^{-1}$ ) and then divided by the specific heat capacity $\left(\mathrm{J} \mathrm{kg}^{-1} \mathrm{~K}^{-1}\right)$. The final magnitude of the tendencies is multiplied by 100 .

hydrometeor due to the corresponding microphysical process; and $N$ is the total number of pixels either in the stratiform or convective region.

The four microphysics schemes share some features of microphysical tendencies. For instance, the convective areas generally have a heating-cooling rate 10 times that in the corresponding stratiform area. Additionally, heating through cloud condensation dominates in the convective regions, resulting in net heating throughout the column (black line in Figs. 8a-d). Conversely, the stratiform areas are characterized by higher cloud and rain evaporation cooling rates, resulting in a total cooling effect near the surface. Several cooling processes (e.g., melting from snow and graupel; sublimation from cloud ice, snow, and graupel; and evaporation from rain and cloud water) occur near the melting layer at $5 \mathrm{~km} \mathrm{AGL}$, leading to strong total diabatic cooling effects in that location (black line in Figs. 8e-h).

Further investigation of the tendency profile of microphysical processes in the convective and stratiform areas reveals that the various microphysics schemes are characterized by different magnitudes and distributions associated with their hydrometeor characteristics (Fig. 8). GCE results in much larger heating rates from cloud condensation and ice deposition in the convective region (Fig. 8a). In addition, the ice 


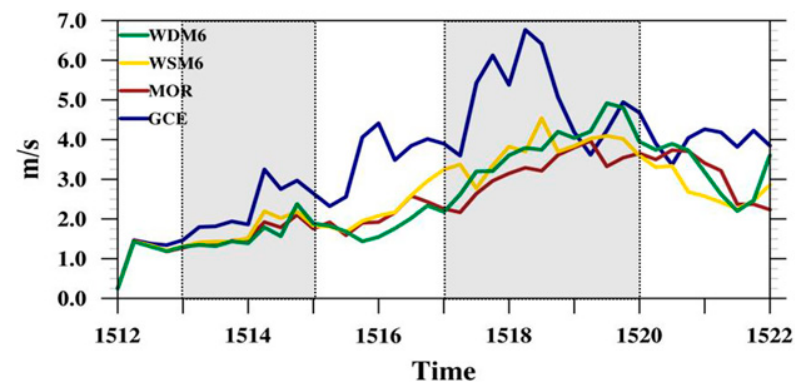

FIG. 9. Time evolution of the vertical velocity $\left(\mathrm{m} \mathrm{s}^{-1}\right)$ averaged over space (black box in Fig. 4) and by vertical level (only the grid points whose vertical velocity is in the top $1 \%$ of each layer are averaged). Black-shaded areas represent fast-error-growth periods as in Fig. 5 .

deposition that peaks at $8 \mathrm{~km}$ AGL is several times more intense than that in other schemes (Figs. 8a,e). Such a unique feature results from the saturation adjustment methods proposed by Tao et al. (1989). By contrast, MOR obtains the least cloud condensation in the midlayer (Figs. 8b,f), resulting in less latent heat being released and weaker vertical development of the convection (reflectivity $>30 \mathrm{dBZ}$ exists only at $<6 \mathrm{~km}$ AGL in Fig. 5b). The larger raindrop radius and lower $q_{r}$ in MOR lead to the weakest rain-evaporation-related cooling processes (Figs. 8b,f). Compared with WSM6, WDM6 generally exhibits larger warm-rain-related microphysical tendencies (Figs. 8c,d,g, and h). Moreover, the prominent rain evaporation of WDM6 results in a broader cold pool region (not shown), similar to that found by Lim and Hong (2010). Although the two schemes have a similar ice-phase distribution (Fig. 7), WDM6 generally exhibits stronger tendencies than WSM6 does, possibly due to the different shape parameters $\left(\mu_{r}=1\right.$ and 0 , respectively).

In the case study, GCE produces the largest magnitude in almost every microphysical diabatic heating-cooling process among all the schemes, particularly for the ice-phase tendencies (Figs. 8a,e). Such results reveal that the phase transition between hydrometeors is relatively efficient in GCE, and hence a larger energy transformation occurs during convective development. The temporal evolution of upward motion (Fig. 9) also supports this conclusion; GCE not only generates the largest vertical velocity during the whole period, but its magnitude also reaches its peak more quickly than it does in other schemes.

\section{b. Ensemble forecast: Forecast uncertainty evaluation of various microphysics schemes}

In this subsection, the standard deviations among the ensemble members define the ensemble spread and represent the forecast uncertainty. The characteristics of the standard deviation, its temporal evolution, and the vertical structures of different prognostic variables are evaluated using a horizontally averaged time-height diagram.

\section{1) UNCERTAINTIES IN HYDROMETEORS}

By using the K-means algorithm for cluster analysis (Christiansen 2007), the quantitative precipitation forecast of the 36 ensemble members can be divided into four subensemble groups (not shown): two of them have heavy rainfall near the coastal area, one has heavy rainfall inland, and the other one is over the ocean. Figure 10 shows the specific outcomes of the convective distribution from the various fixed-microphysics ensembles, where the column-maximum radar reflectivity is presented. Three members belong to different subgroups ( $\mathrm{m} 10, \mathrm{~m} 19$, and $\mathrm{m} 35$ refer to coastal, inland, and overseas subgroups, respectively) are selected to indicate the precipitation diversity. Considerable variability in the location, amount, and pattern of the convective system is observed for simulations using different initial conditions, suggesting that the uncertainty in the initial state dominates the overall pattern of the weather system and hence the forecast uncertainty. Although initial conditions determine the general distribution of precipitation systems, the intensity and location of convective cores are sensitive to the use of different microphysics schemes (Fig. 6). The range of the convective diversity can also be viewed using the probabilistic approach, as shown in Fig. 11, which illustrates the neighborhood ensemble probability (Ebert 2008) for each ensemble. This method generates a probabilistic forecast at each grid point by collecting nearby points that exceed a given threshold $(20 \mathrm{dBZ})$ in all members within a specified distance $(6 \mathrm{~km})$ to mitigate spatial deviation in the model simulation. Figure 11 demonstrates a broad coverage of the precipitation distribution among the 36 members for different microphysics schemes, as the $10 \%$ probability contour occurs over the offshore area of southwestern and eastern Taiwan. In addition, a higher probability $(>50 \%)$ is found near the coastal area in southwestern Taiwan, which is in agreement with the observations (Fig. 1c). Such a result suggests that the ensemble mean approaches reality, and the ensemble dispersion is sufficiently large to represent the possible location of precipitation in this strongly nonlinear convective system.

Figures 12 and 13 present the standard deviation evolution for different hydrometeors. The four microphysics schemes obtain some common patterns regarding how hydrometeors spread over time. Two periods of fast-error-growth are found during the simulation time: 1300-1500 and 1700-2000 UTC, corresponding to the convective development shown in Fig. 5. During the first fast-error-growth period, the ensemble spread of $q_{i}$ and $q_{c}$ first increases and reaches its maximum at 1330 UTC (Fig. 12). In contrast, the $q_{r}$ spread reaches a plateau at nearly 1400 UTC. That spread of ice-phase hydrometeors responds slower than other warm-rain species in this period because the convection developed less vigorous (Figs. 5 and 9). Similar evolution but with more intense vertical development of ensemble spread for hydrometeors is discovered in the second fast-error-growth period, which corresponds to the most convectively active hours in the simulation (Figs. 5 and 9). During this period, the spread of all hydrometeors evolved quickly. The ensemble spread of $q_{c}$ is the first to reach its peak value (at 1800 UTC), followed by $q_{r}$ (at 1830 UTC), $q_{g}$ (at 1900 UTC), and finally $q_{s}$ (at 2000 UTC; Figs. 12 and 13). Because $q_{r}$ and $q_{g}$ represent the dominant hydrometeors in the convective area (Figs. 7a,c, respectively), their maximum spread occurs when the convective system is most active 
(a) GCE m10

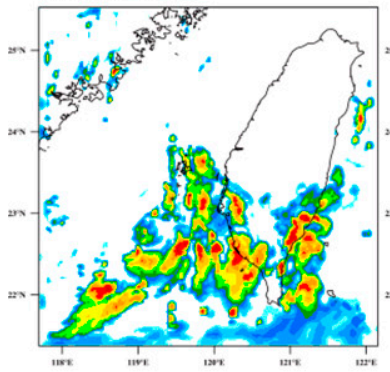

(d) MOR m10

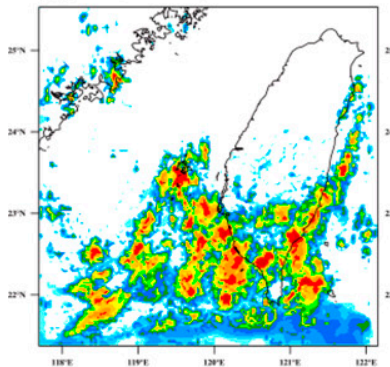

(g) WSM m10

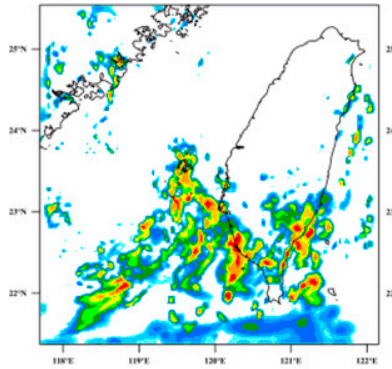

(j) WDM m10

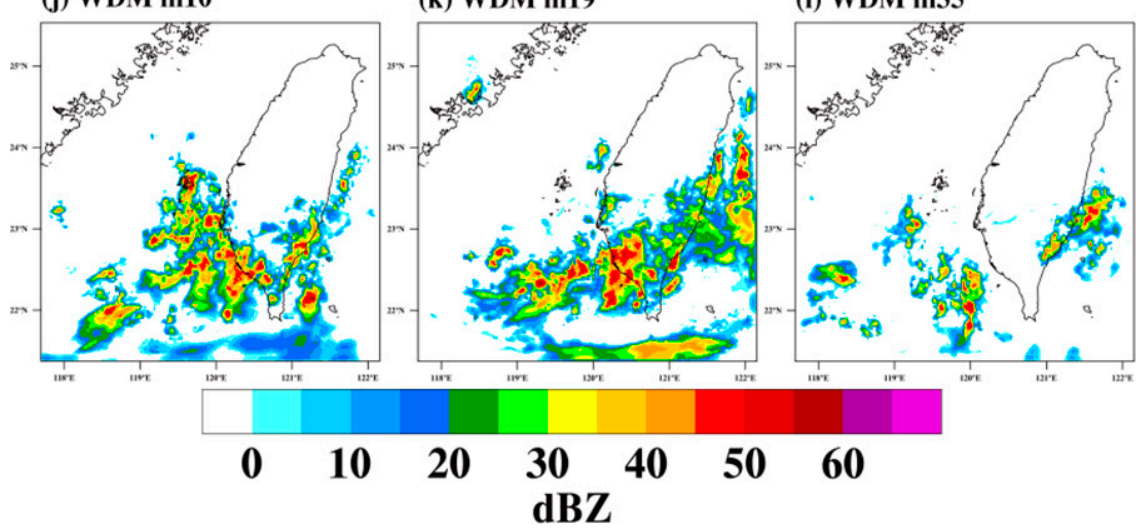

FIG. 10. Distribution of column-maximum model-derived radar reflectivity at 1900 UTC 15 Jun 2008 for members of a fixed-microphysics ensemble: (a)-(c) GCE, (d)-(f) MOR, (g)-(i) WSM6, and (m)-(p) WDM6 schemes. The members that selected from three different clusters [characterized by coastal rainfall (m10), inland rainfall (m19), and oversea rainfall (m35)] are displayed as examples to represent the diversity among the 36-member ensemble forecasts.

(b) GCE m19

(c) GCE m35

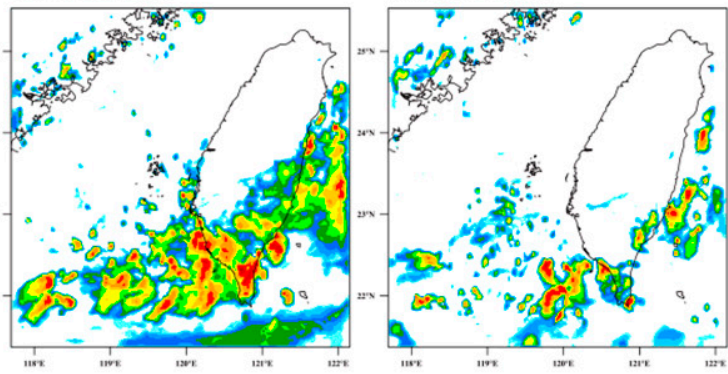

(e) MOR m19

(f) MOR m35

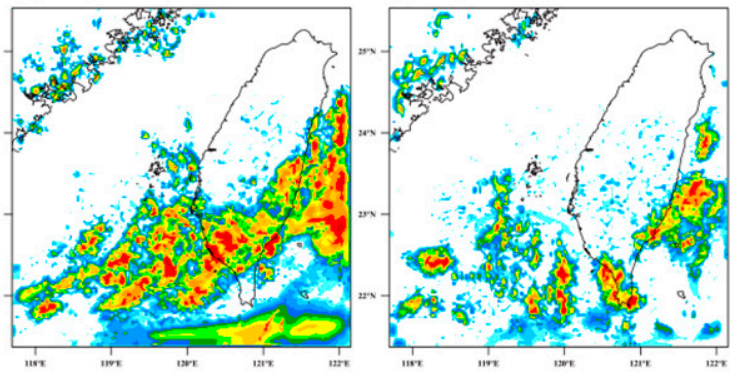

(i) WSM m35

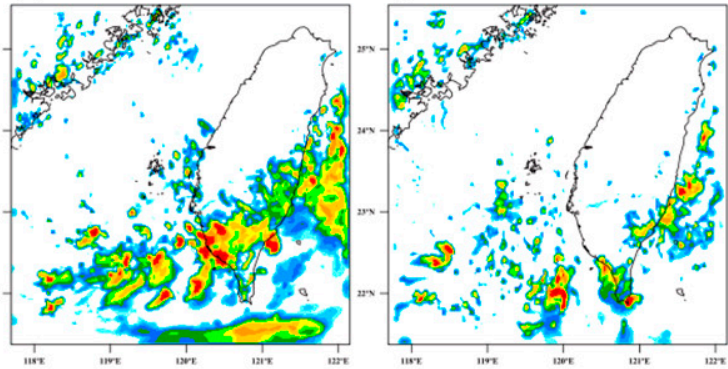

(k) WDM m19

(I) WDM m35

(h) WSM m19

.


(a) GCE thr20

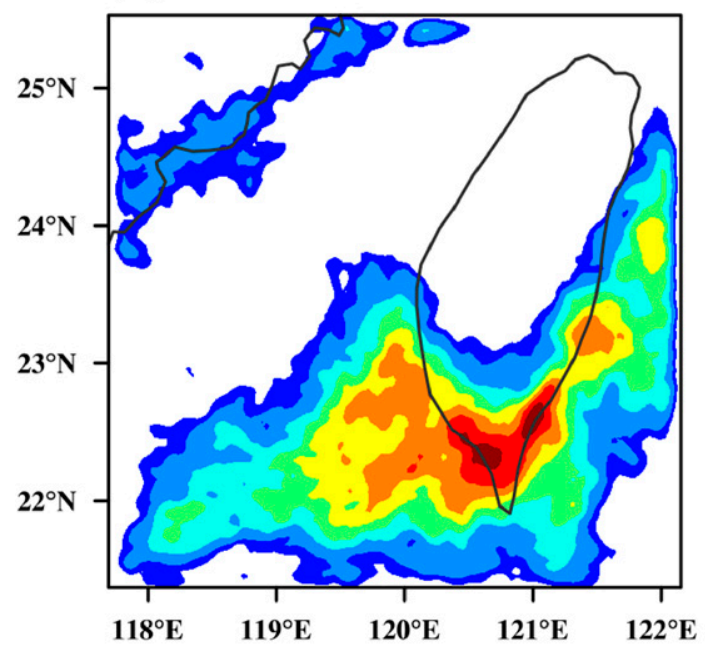

(c) WSM6 thr20

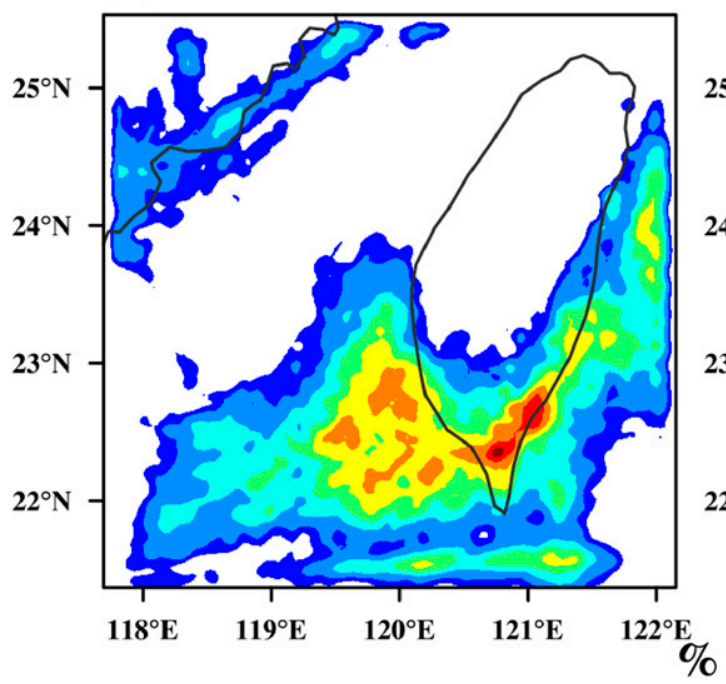

(b) MOR thr20

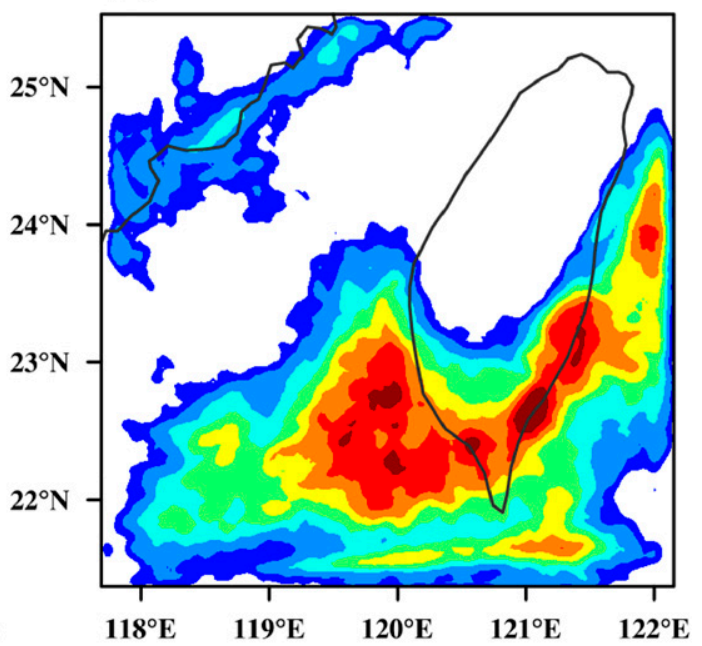

(d) WDM6 thr20

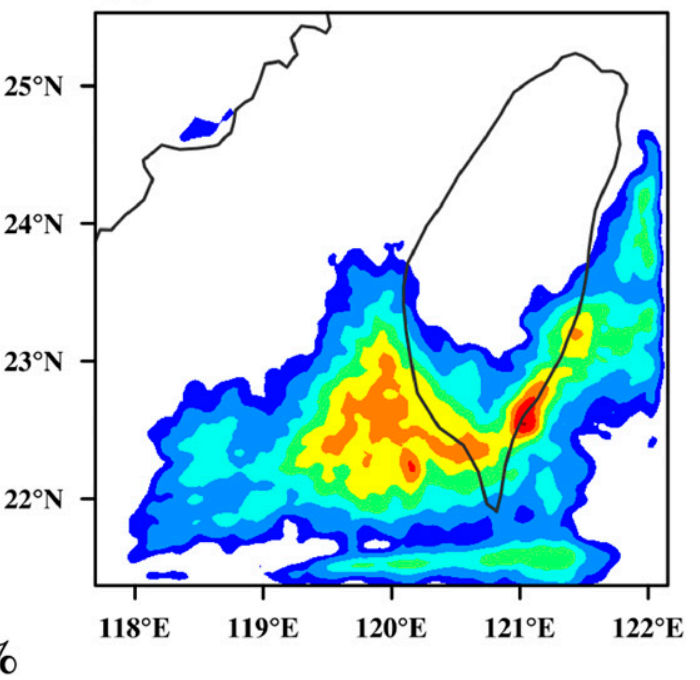

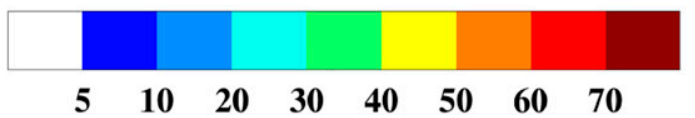

FIG. 11. Neighborhood ensemble probability of column-maximum model-derived radar reflectivity $>20 \mathrm{~dB} Z$ over a radius of $6 \mathrm{~km}$ at 1900 UTC 15 Jun 2008 for the (a) GCE, (b) MOR, (c) WSM6, and (d) WDM6 schemes.

(Figs. 5 and 9). By contrast, the peak spread of $q_{s}$, which dominates the stratiform area (Fig. 7i), is closely related to the dissipation stage of the precipitation system. The ensemble spread of $q_{i}$ evolves differently in these two periods: in the first, the evolution of $q_{i}$ spread is synchronized with that of $q_{c}$, whereas in the second period, $q_{i}$ spread shows little growth except for GCE that presents maximum value after 2000 UTC (Fig. 12). Furthermore, the peak spread of $q_{r}$ is delayed with increasing height, which then converts to $q_{g}$ above the melting layer (i.e., tilting structure in Fig. 13), indicating that the convection is evolving upward.
When compared with the results for different microphysics schemes in section $3 \mathrm{a}$, the forecast uncertainties in the hydrometeors' structure produced by these fixed-microphysics ensembles correspond to the behaviors seen in the deterministic forecasts. For example, GCE results in a much larger spread of ice-phase species (Figs. 12a and 13a), corresponding to its larger magnitudes of $q_{g}, q_{s}$, and $q_{i}$ (Fig. 7). By contrast, MOR produces the least spread of all hydrometeors (Figs. 12b and $13 \mathrm{~b}$ ), corresponding to its lowest mixing ratios of hydrometeors (Fig. 7). Although the overall uncertainty structures for WSM6 and WDM6 are similar, the ensemble with WDM6 
(a) GCE

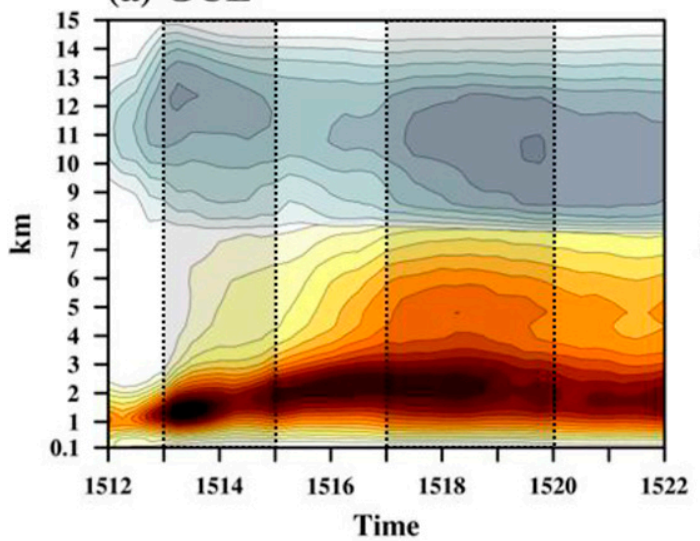

(c) WSM6

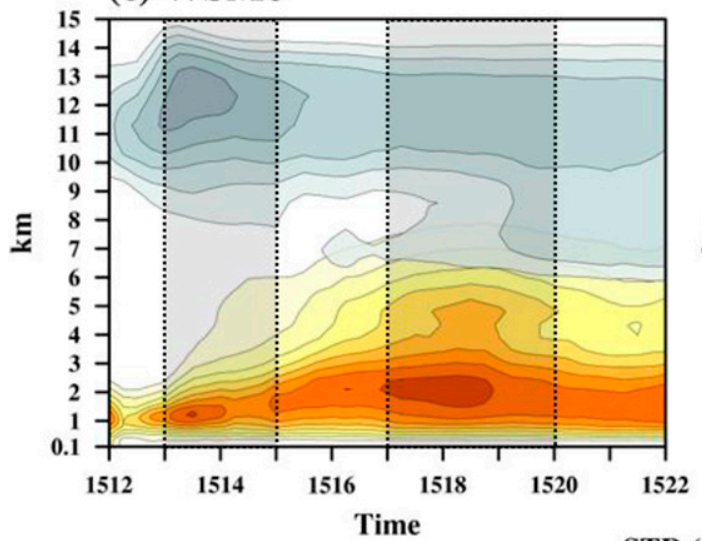

(b) MOR

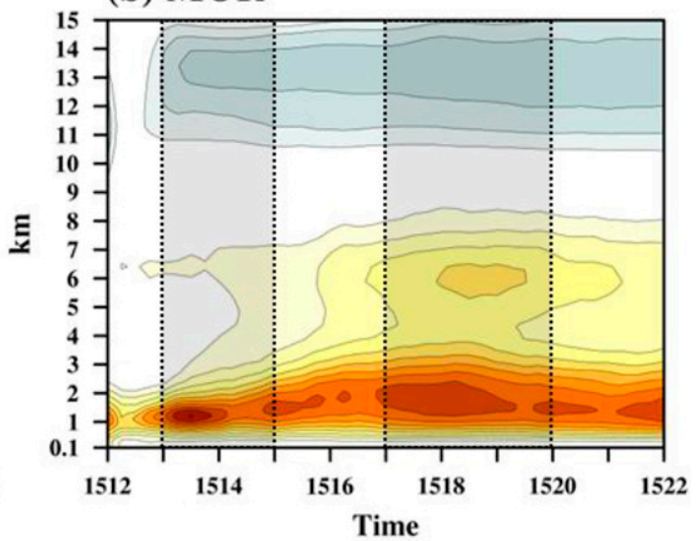

(d) WDM6

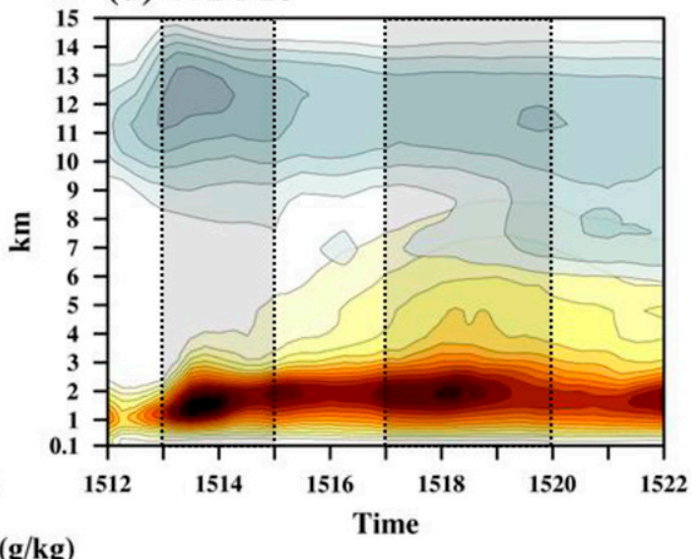

STD (g/kg)

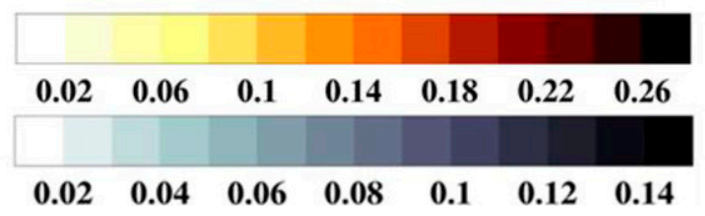

FIG. 12. Time-height cross section of the standard deviation of the cloud water mixing ratio $\left(\mathrm{g} \mathrm{kg}^{-1}\right)$ (brown shaded) and cloud ice mixing ratio (gray shaded) simulated by the (a) GCE, (b) MOR, (c) WSM6, and (d) WDM6 schemes. Black-shaded areas represent fast-error-growth periods as in Fig. 5.

produces a larger spread of all hydrometeors, particularly for $q_{c}$ and $q_{r}$; this larger spread is due to the double-moment treatment of warm rain processes (Figs. 12c,d and 13c,d). Notably, although WSM6 and WDM6 have a similar magnitude of $q_{c}$ (Figs. 7b,g), WDM6 can create a much larger $q_{c}$ spread than WSM6 can. Furthermore, the differences in warm rain microphysical processes feedback to the thermodynamical and dynamical state variables, subsequently impacting the ice-phase species, resulting in a larger spread of $q_{s}$ and $q_{g}$ for WDM6. This result implies that the ensemble that adopts double-moment parameterization could be more sensitive to the same initial condition uncertainty than the single-moment counterpart under a similar design structure.

\section{2) UNCERTAINTIES IN THERMODYNAMIC AND DYNAMIC VARIABLES}

Diabatic processes involved in water phase changes play a critical role in the development of a convective system. Figure 14 displays the standard deviation of the total latent heat release (the net effect of diabatic heating and cooling). In the first fast-error-growth period, the ensemble spread of heat release mainly concentrates near $1 \mathrm{~km}$ AGL in all experiments, corresponding to a large variation in the condensation heating and evaporation cooling effects induced by the $q_{c}$ spread (Fig. 12). In the second fast-error-growth period, the largest spread is around $4-6 \mathrm{~km} \mathrm{AGL}$, and the peak occurs at 1830 UTC. This feature corresponds to the 
(a) GCE

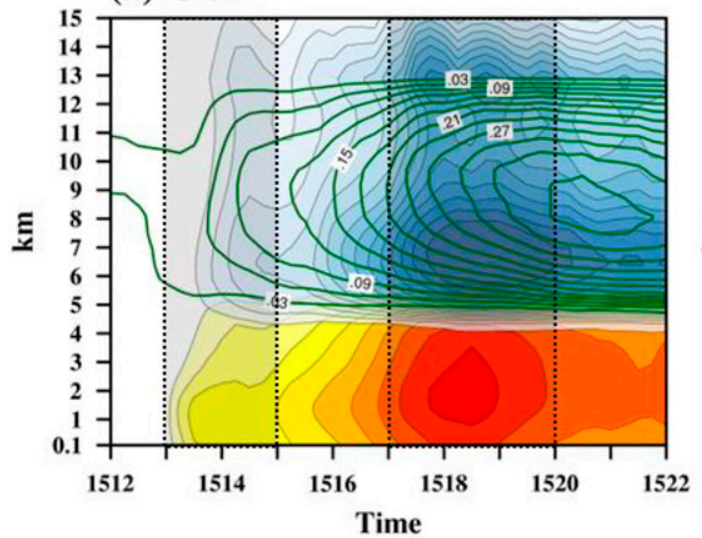

(c) WSM6

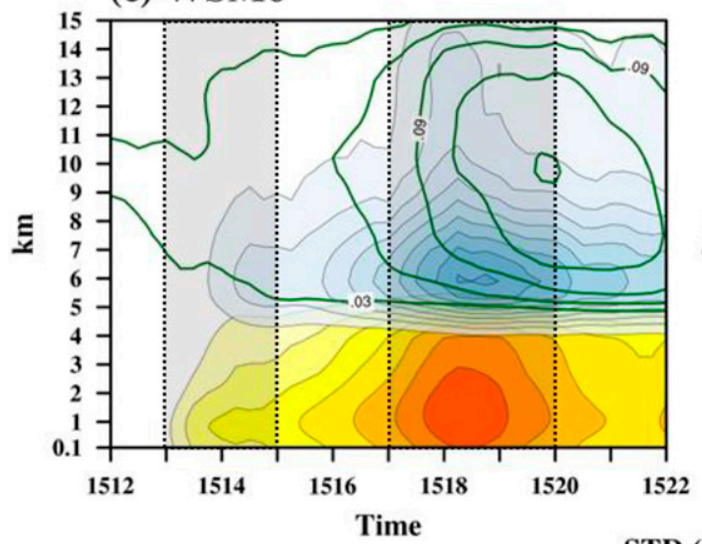

(b) MOR

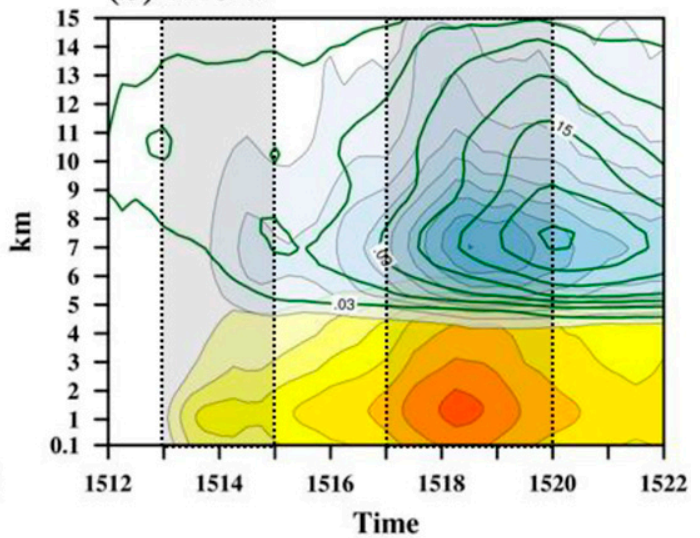

(d) WDM6

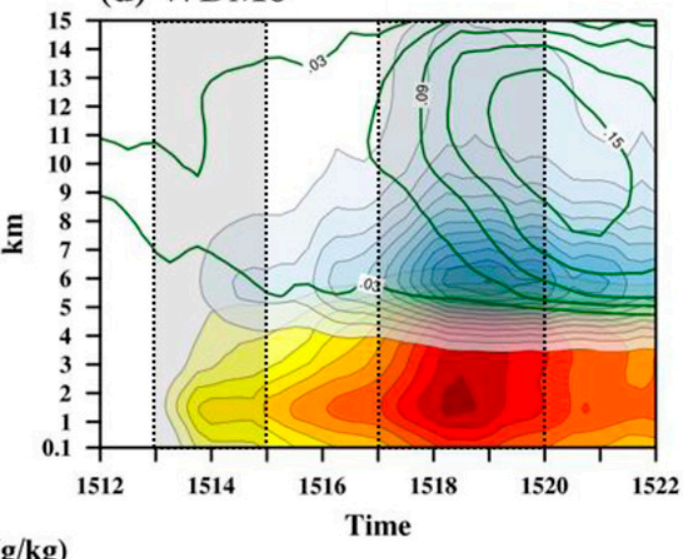

$\operatorname{STD}(\mathrm{g} / \mathrm{kg})$

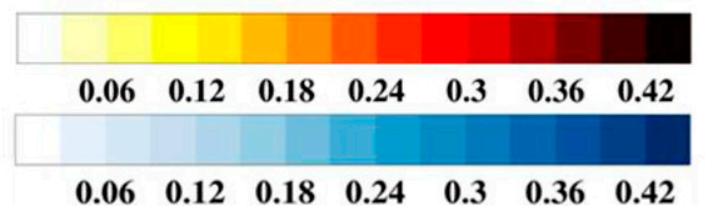

FIG. 13. Time-height cross section of the standard deviation of the rainwater mixing ratio ( $\mathrm{g} \mathrm{kg}^{-1}$; yellow to red shaded), graupel mixing ratio (blue shaded), and snow mixing ratio (green contour)s simulated by the (a) GCE, (b) MOR, (c) WSM6, and (d) WDM6 schemes. Black-shaded areas represent fast-error-growth periods as in Fig. 5.

establishment of a mature convective system, where the transition between water species become active, particularly near the melting layer. Consequently, the ensemble spread of latent heat release contributed by these heating-cooling processes is typically large within the melting layer at $5 \mathrm{~km}$ AGL.

Among the fixed-microphysics experiments, GCE results in the most significant spread in the total latent heat release (Fig. 14a), which is associated with active phase transitions between water species (Figs. 8a,e) and the most vigorous vertical velocity (Fig. 9) obtained in deterministic forecasts. During the mature stage of the convective system, GCE produces a large ensemble spread of latent heat release at $8-9 \mathrm{~km}$ AGL, which is contributed to by the distinct ice deposition process shown in Figs. 8a,e. By contrast, MOR generates the least spread of latent heat release (Fig. 14b), which is due to the less active microphysics processes (Figs. 8b,f) and the weakest vertical velocity (Fig. 9). This negative feedback process would likely further hamper its ability to generate additional hydrometeors and subsequent ensemble spread. As expected, the ensemble spread of latent heat release is larger in WDM6 than in WSM6, particularly beneath the melting layer (Figs. 14c,d), where $q_{c}$ induced condensation heating is the dominant heating source (Fig. 12d).

Figures 15 and 16 present the standard deviation associated with temperature and horizontal wind. During the first fast-error-growth period, the temperature spread peak at 2 $\mathrm{km}$ AGL in all experiments (Fig. 15) in response to the 
(a) GCE

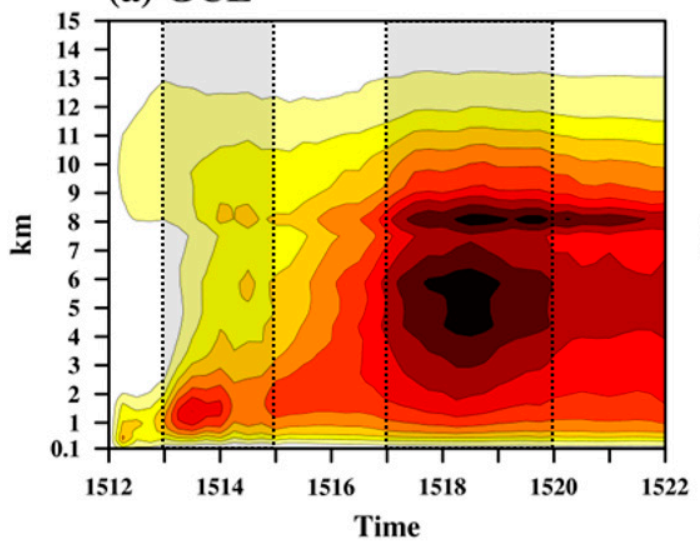

(c) WSM6

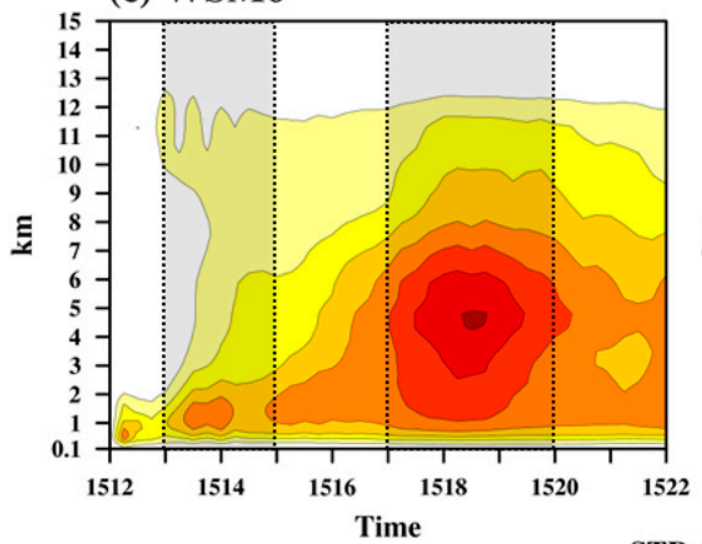

(b) MOR

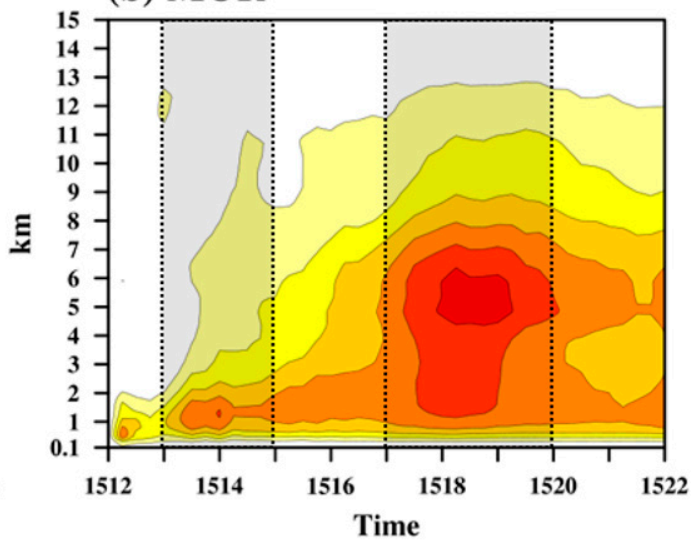

(d) WDM6

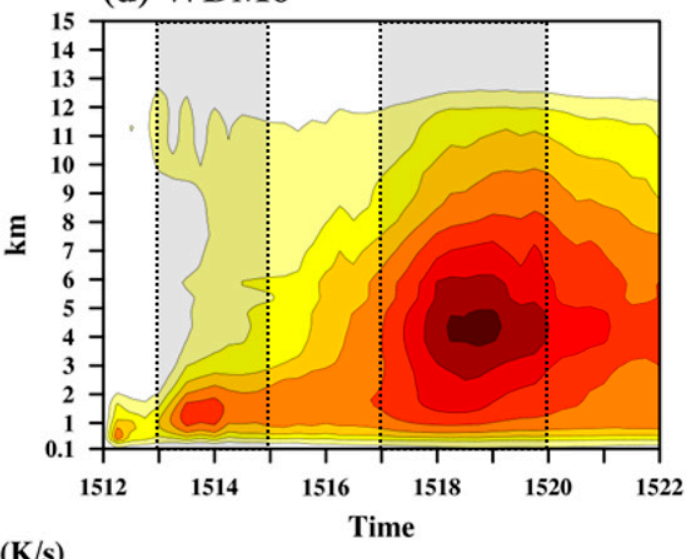

$\operatorname{STD}(\mathbf{K} / \mathbf{s})$

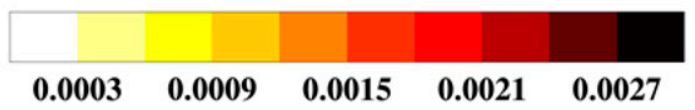

FIG. 14. Time-height cross section of the standard deviation of the total latent heat release rate $\left(\mathrm{K} \mathrm{s}^{-1}\right)$ for the (a) GCE, (b) MOR, (c) WSM6, and (d) WDM6 schemes. Black-shaded areas represent fast-error-growth periods as in Fig. 5.

latent heat release uncertainty (Fig. 14). Similar patterns are observed during the mature stage of the convective system, at which point the temperature spread grows again because of the latent heating-cooling in the midtroposphere. The peak value occurs between 2000 and 2100 UTC at $4 \mathrm{~km} \mathrm{AGL}$, approximately two hours later than the latent heat release. Moreover, the magnitude of temperature spread remains at higher values for longer into the forecast than those of the microphysics-related variables (Figs. 12-14).

Regarding horizontal wind's forecast uncertainty (Fig. 16), the vertical structure and magnitude differences among microphysics schemes are smaller than the temperature spreads. The growth rate of the ensemble spread for wind speed is much smoother than that of temperature. Two peaks are noted in the vertical during the mature stage of the convective system. The first peak (at $1 \mathrm{~km}$ ) corresponds to low-level convergence and convective evolution, whereas latent heating and mesovortex circulation cause the second peak (at $4-5 \mathrm{~km}$ ). Both the temperature and wind fields are characterized by a large ensemble spread above $10 \mathrm{~km}$ AGL, especially during spinup. Such features are caused by the forecast uncertainty in the synoptic-scale weather patterns. This uncertainty is generated by the variation of trough location, as mentioned in section $2 \mathrm{a}$, and is incorporated into the initial conditions.

GCE produces the largest temperature and wind speed spreads above the melting layer, associated with its greatest uncertainty in ice-phase processes (Figs. 12a and 13a). By contrast, the WDM6 ensemble is generally characterized by a greater temperature spread (Fig. 15d) below the melting layer. The $q_{g}$ spread for WDM6 extends to a lower altitude, and it can contribute to the diversity in the temperature field (Fig. 13d). The existence of $q_{g}$ spread at a lower level 
(a) GCE

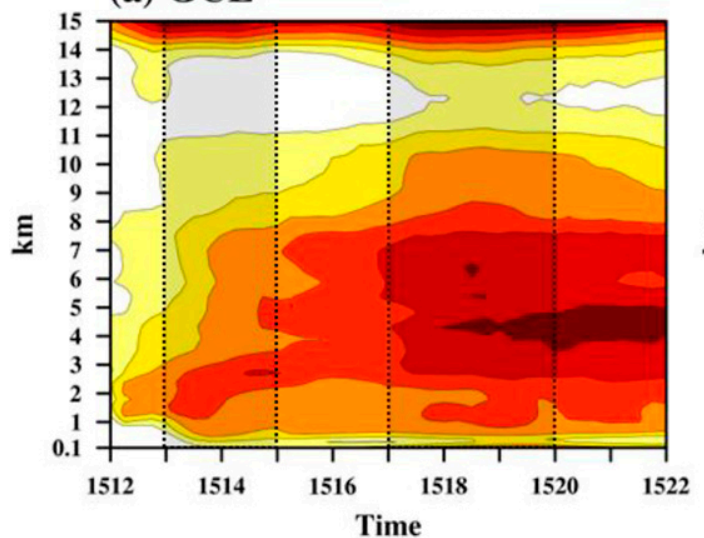

(c) WSM6

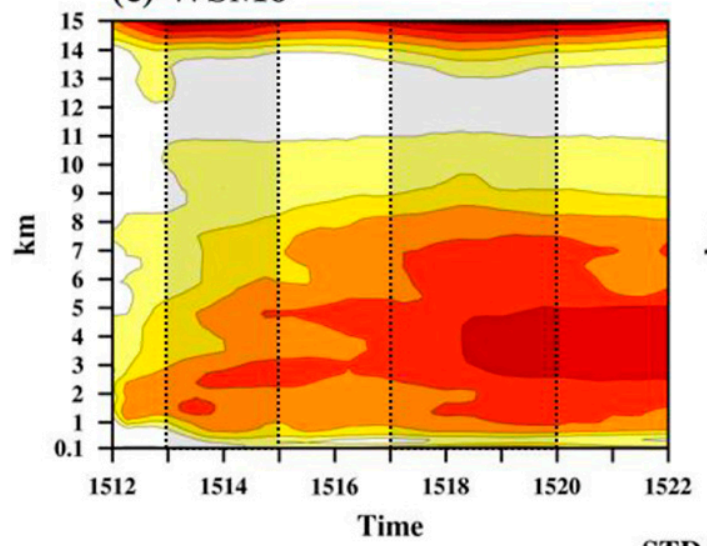

(b) MOR

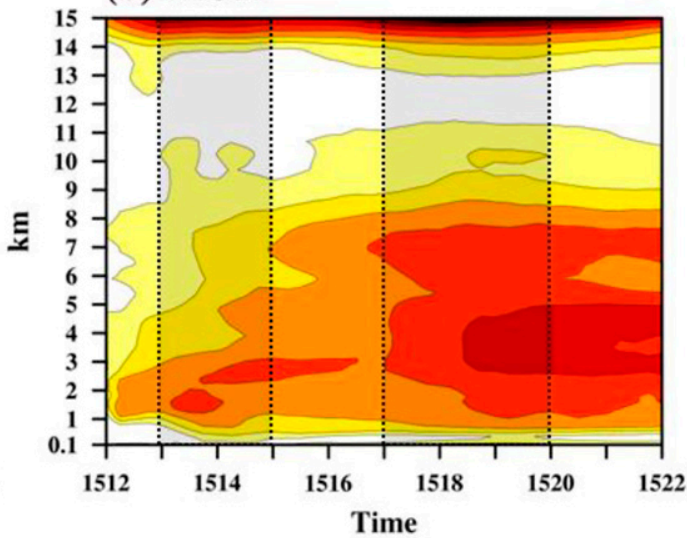

(d) WDM6

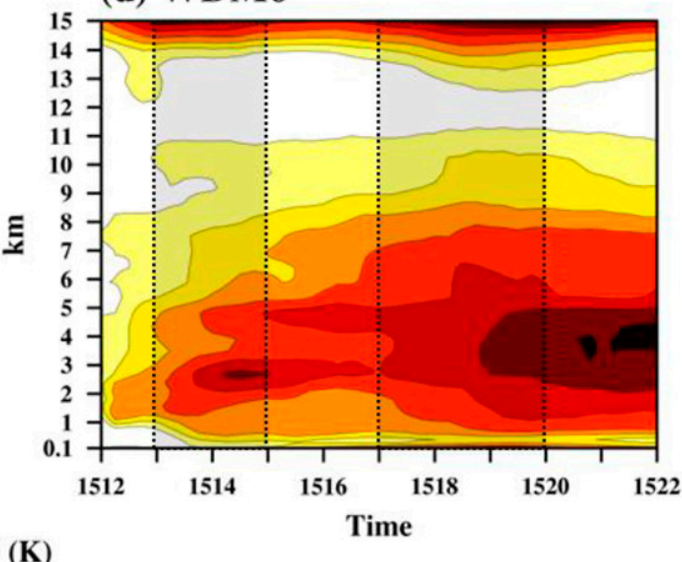

STD (K)

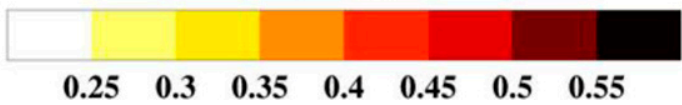

FIG. 15. Time-height cross section of the standard deviation of the temperature (K) for the (a) GCE, (b) MOR, (c) WSM6, and (d) WDM6 schemes. Black-shaded areas represent fast-error-growth periods as in Fig. 5.

is a unique behavior in WDM6; this can be confirmed from the deterministic forecasts, in which the $q_{g}$ in WDM6 exists at a lower layer than that in other schemes (Fig. 7c), causing the graupel melting process to occur there (Fig. 8d).

The time series of the domain-averaged (black box in Fig. 4) RMDTE is illustrated in Fig. 17 to quantify the total ensemble spread growth associated with dynamic and thermodynamic fields in the various microphysics schemes. In the first hour of simulation, four schemes have nearly identical growth rates, consistent with the finding of Wang et al. (2012), who showed that a parameterization scheme that has different complexities presents similar error growth rates in the first 1-2 h of a model simulation. Furthermore, the error growth in the strong convection region is more prominent than that in the whole d03 domain (Fig. 17); this indicates that the moist convection process contributes considerably to the growth of forecast uncertainty (Zhang et al. 2002, 2003; Tan et al. 2004).

The RMDTEs for the schemes begin to differ after 1300 UTC and increase more quickly during the second fast-error- growth period. Of the four microphysics schemes, GCE starts growing RMDTE sooner than other experiments and generally has the largest RMDTE during the simulation time. WDM6 also has a rapid growth rate during 1700-1900 UTC, which can be connected to the fastest growth of $q_{r}$ uncertainty produced by this scheme (Fig. 13d). Such a phenomenon might correspond to the melting of graupel, amplifying the ensemble spread of diabatic heating-cooling and further enhancing the uncertainty in the thermodynamic variables (Fig. 15d). MOR and WSM6 have smaller RMDTEs. The RMDTE results reveal that GCE and WDM6 are more sensitive to initial condition uncertainty, whereas MOR and WSM6 are relatively less sensitive to that for this event. Generally, the error in the four schemes becomes saturated after $8 \mathrm{~h}$ of model simulation (2000 UTC).

To further investigate the growth rate of ensemble spread at different spatial scales, Fig. 18 presents the spectrum analysis of the RMDTE. The spatial scale is separated into small $(L<30 \mathrm{~km})$, intermediate $(L=30-150 \mathrm{~km})$, and large 
(a) GCE

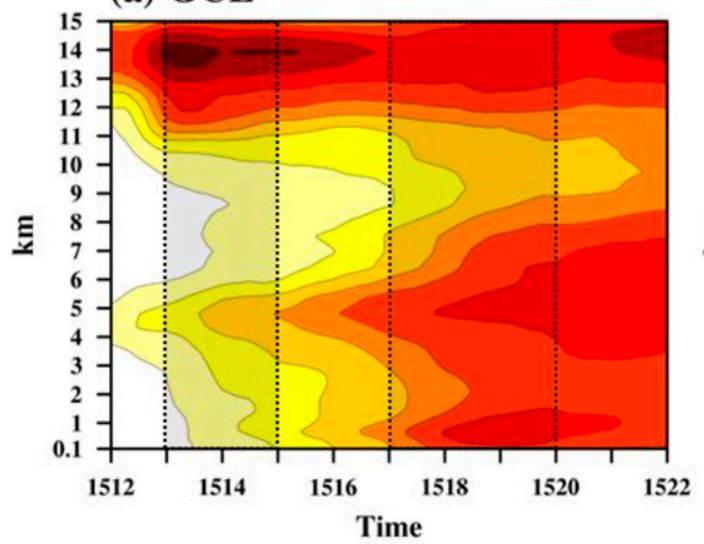

(c) WSM6

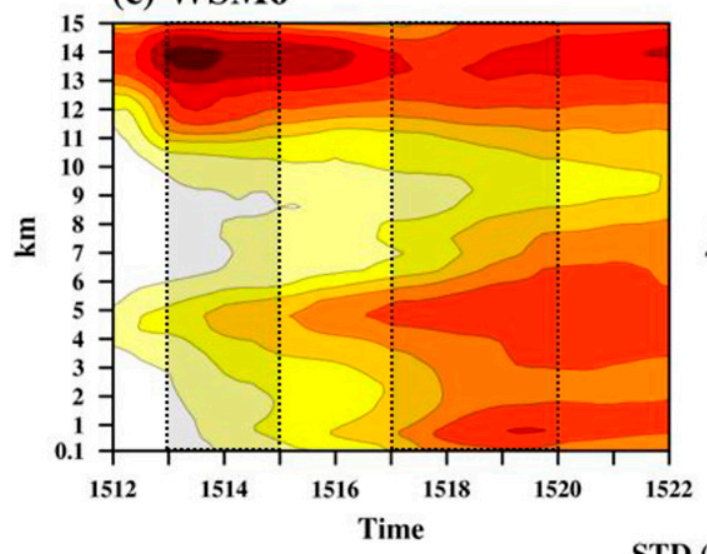

(b) MOR

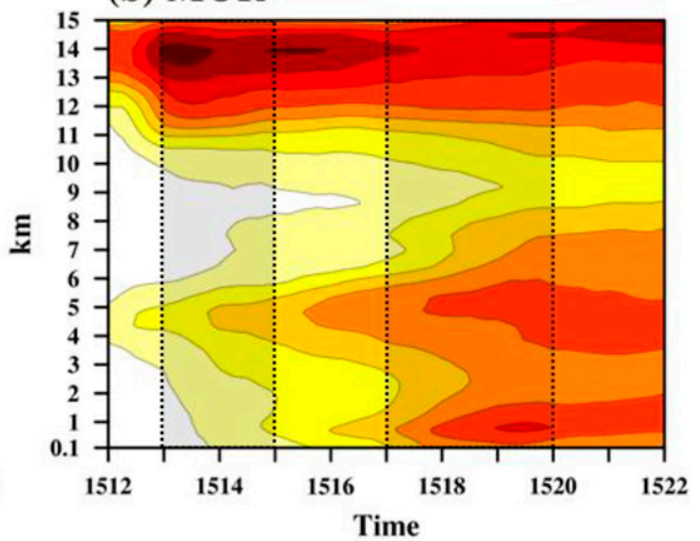

(d) WDM6

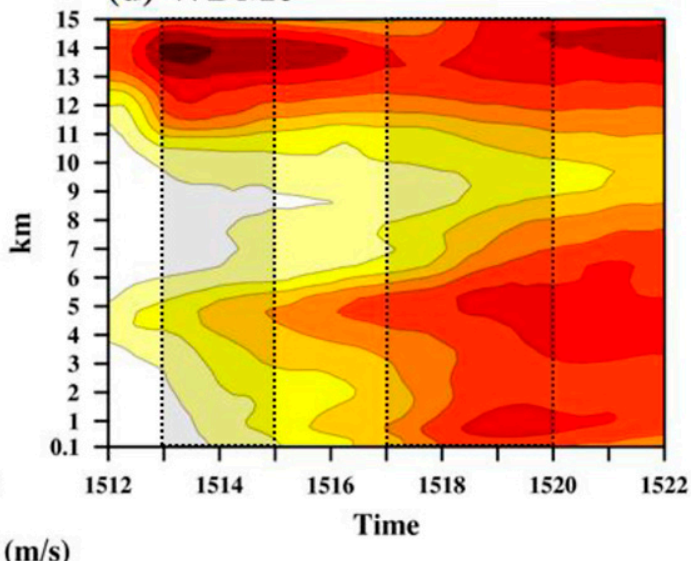

$\operatorname{STD}(\mathbf{m} / \mathbf{s})$

$\begin{array}{lllllllll}1.1 & 1.3 & 1.5 & 1.7 & 1.9 & 2.1 & 2.3 & 2.5 & 2.7\end{array}$

FIG. 16. Time-height cross section of the standard deviation of the horizontal wind speed ( $\mathrm{m} \mathrm{s}^{-1}$ ) for the (a) GCE, (b) MOR, (c) WSM6, and (d) WDM6 schemes. Black-shaded areas represent fast-error-growth periods as in Fig. 5.

( $L>150 \mathrm{~km}$ ) scales following Zhang et al. (2007). In general, the small-scale RMDTE grows rapidly during the first $1.5 \mathrm{~h}$ of the model simulation (square lines in Fig. 18) due to the dynamical spinup process. In the intermediate scale, the RMDTE has a relatively high growth rate during 1530-1730 UTC (triangular lines in Fig. 18), whereas in the large scale, the growth rate is lower, and a somewhat clearer growth period occurs during 1730-1930 UTC (diamond lines in Fig. $18 \mathrm{~b}$ ), which is the final period of growth among the three scales. This upscale growth pattern agrees with the threestage error growth model proposed by Zhang et al. (2007). In addition, large-scale RMDTE correlates strongly with the overall RMDTE since its uncertainty has already been involved in the initial condition, which quickly propagates downscale to the shortest wavelengths (Durran and Gingrich 2014). After $7 \mathrm{~h}$ of model integration (1900 UTC), the small-scale RMDTE has plateaued. Toth and Kalnay (1997) indicated that the nonlinear instabilities of different temporal and horizontal scales have different error growth rates. Small-scale nonlinear instability, such as convectivescale instability, has the fastest error growth rate and becomes saturated the soonest.

Among all schemes, GCE and WDM6 have the highest small-scale error growth rate in the early simulation stage. Therefore, in the subsequent forecast lead time, the mechanism of upscale growth makes GCE and WDM6 have a high growth rate after the $3 \mathrm{~h}$ of integration in the intermediate scale and after the $5 \mathrm{~h}$ of integration in the large scale. These results also suggest that GCE and WDM6 respond rapidly to initial condition perturbations for such multiscale feedback when considering the investigated event.

\section{Summary and discussion}

This study explored the differences in the ensemble spread generated by four microphysics schemes-GCE, WSM6, MOR, and WDM6-with one extreme case study to 


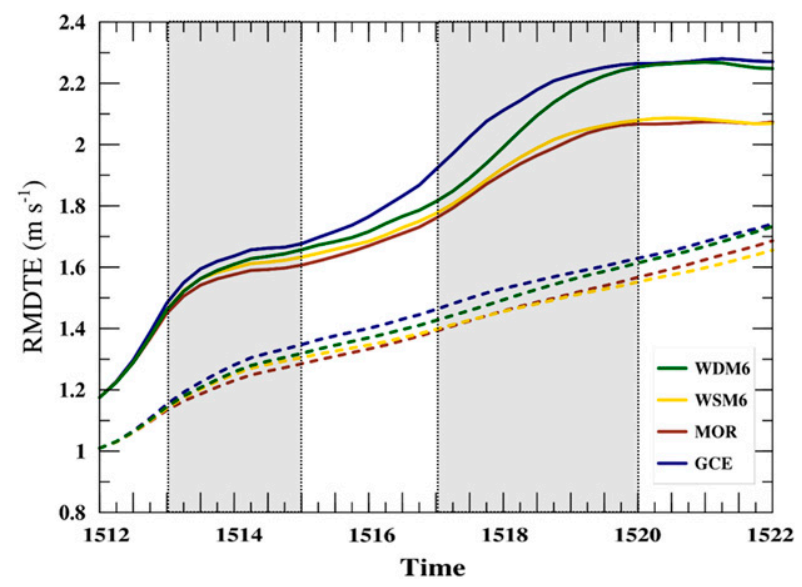

FIG. 17. Time series of the domain-averaged RMDTE. Solid lines highlight the region where the mesoscale convective system occurs (black box in Fig. 4), whereas the dashed lines represent the average over the whole d03 with blue for GCE, red for MOR, yellow for WSM6, and green for WDM6 schemes. Black-shaded areas represent fast-error-growth periods as in Fig. 5.

understand microphysics-scheme-related forecast uncertainty. The deterministic forecast is illustrated to characterize the behaviors of these microphysics schemes, and the forecast uncertainty in several state variables from these schemes is evaluated through ensemble forecasting given the same initial condition perturbations. The key findings are summarized as follows:

1) Given the same initial condition uncertainty, the evolution and vertical structure of the ensemble spread produced by the different fixed-microphysics ensembles are closely related to the features of each microphysics scheme presented in the deterministic forecasts. GCE and WDM6 are more sensitive to initial condition uncertainty than the other two are, and they generally produce a larger ensemble spread for kinematic, thermodynamic, and hydrometeor variables. By contrast, MOR and WSM6 have relatively low spread in these state variables, indicating that the increased ensemble spread in the hydrometeors and latent heat release in each scheme corresponds to an efficient transition from water vapor to other hydrometeor variables, resulting from active diabatic heating-cooling processes and strong vertical velocity; this induces large uncertainty in the small-scale microphysical processes. Furthermore, the convective-scale errors quickly grow and affect large-scale uncertainties in temperature and horizontal wind. WSM6 and WDM6 treat ice-phase processes similarly and obtain almost the same vertical structure in the ice-phase uncertainties.

2) Although double-moment schemes can better describe the particle size distribution of hydrometeors than single-moment schemes can, the results obtained for the investigated event illustrate that the double-moment schemes (MOR and WDM6) do not necessarily produce a larger ensemble spread than the single-moment schemes do (GCE and WSM6). Instead, microphysics schemes characterized by more active microphysical processes (i.e., more diabatic heating-cooling effects) can generate more ensemble spread. However, a comparison of two similar schemes (WSM6 and WDM6) reveals the double-moment parameterization is more sensitive to the initial condition perturbations. The double-moment treatment of warm rain processes in WDM6 leads to a larger ensemble spread in $q_{c}$ and $q_{r}$, resulting in larger uncertainty in the latent heat release than in WSM6. Consequently, the feedback from warm rain microphysical processes to dynamics and thermodynamics variables gradually affects the uncertainty in ice-phase species at a higher level during the vertical development of convection, thereby resulting in an overall larger ensemble spread in WDM6 for all state variables. This result implies that greater uncertainty stems from a more complicated double-moment process treatment when the microphysics schemes' mechanisms are similar.

3) In this case study, the forecast uncertainty interactions between the convective-scale cloud physics variables and the large-scale dynamical and thermodynamical variables are similar in each microphysics scheme. The initial condition uncertainty that incorporates synopticscale forcing is established rapidly, and it strongly affects the early stage of error growth. For example, the low-level convergence uncertainty due to initial conditions triggers the water vapor to convert into cloud water through condensation, simultaneously increasing the spread of $q_{c}$ and the latent heat release. Subsequently, the more condensation, the more cloud water is made available for rain growth, increasing the $q_{r}$ uncertainty. Afterward, these small-scale uncertainties gradually propagate upscale and increase the uncertainty of temperature fields and the horizontal wind field. During the second fast-error-growth period, convergence uncertainty, resulting from the previously established temperature and wind fields, again triggers uncertainty related to the small-scale variables, forming a positive feedback loop.

In summary, this study illustrates the response of different fixed-microphysics ensembles to the initial conditions. It shows that the conditional sensitivity of ensemble spread to the initial state perturbation is mainly inherited from their deterministic behaviors. Some microphysics schemes can produce a larger ensemble spread because they are more sensitive to initial condition uncertainty due to their increased efficiency in converting water vapor to hydrometeors and the subsequent positive feedback processes. Although only one case study was performed, the present results provide the strategy for improving both convective-scale ensemble prediction and ensemble-based data assimilation systems. For ensemble prediction systems, different microphysics schemes in a multimicrophysics ensemble should be selected carefully given the limited computation, sufficient ensemble spread should be produced, and the overall forecast uncertainty 
(b) larger scale RMDTE

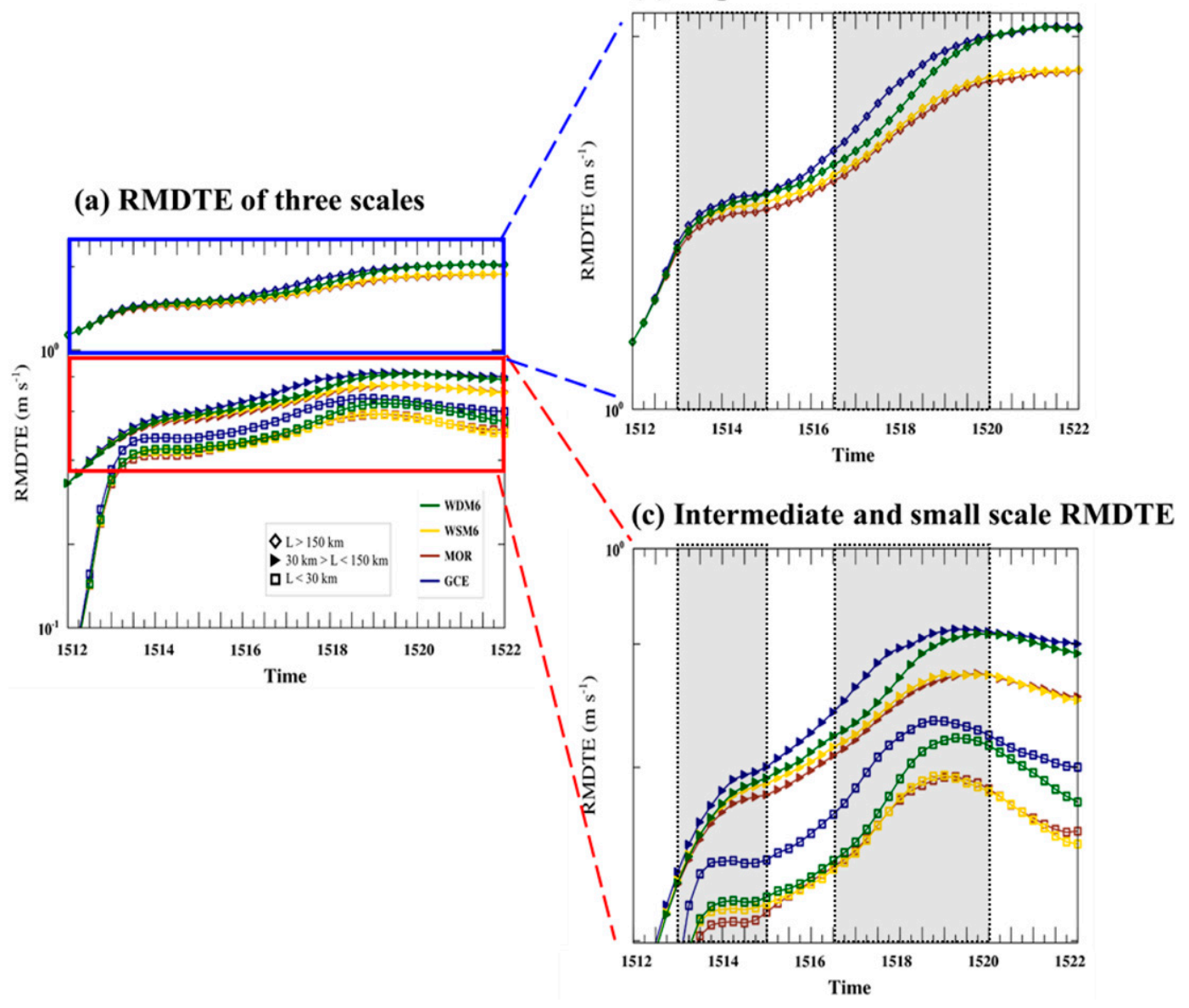

FIG. 18. (a) Time series of three spatial scales of the RMDTE (displayed in logarithmic scale), where the lines of squares, triangles, and diamonds represent the small-scale spread $(L<30 \mathrm{~km})$, intermediate-scale spread $(30<L<$ $150 \mathrm{~km})$, and large-scale spread $(L>150 \mathrm{~km})$, respectively. Blue for GCE, red for MOR, yellow for WSM6, and green for WDM6 schemes. Enlarged sections of the (b) large-scale RMDTE time series and (c) intermediate- and smallscale RMDTE time series. Black-shaded areas represent fast-error-growth periods as in Fig. 5.

could be represented. On the other hand, ensemble-based data assimilation systems that usually focus on adopting only one microphysics scheme, selecting a microphysics scheme that is sensitive to the initial conditions and rapidly increases the ensemble spread in the spinup stage is desirable to ensure that the observations can be assimilated more effectively.

The evaluation of forecast uncertainty produced by different microphysics schemes in this study reveals several encouraging results in short-term forecasts. Still, a more rigorous examination of varying weather systems (e.g., typhoons and thunderstorms) is required to provide broader results. Furthermore, different microphysics parameterization types should be investigated, such as the multimoment or even the bin model, which may more flexibly describe the microphysical processes.

Acknowledgments. We appreciate three anonymous reviewers for their invaluable comments to improve the quality of the manuscript. This work was supported by the Ministry of
Science and Technology of Taiwan under Research Grants 106-2111-M-008-020, 107-2111-M-008-003-MY3, and 104-2923M-008-003-MY5.

\section{REFERENCES}

Chang, P.-L., P.-F. Lin, B. Jong-Dao Jou, and J. Zhang, 2009: An application of reflectivity climatology in constructing radar hybrid scans over complex terrain. J. Atmos. Oceanic Technol., 26, 1315-1327, https://doi.org/10.1175/2009JTECHA1162.1.

Chang, W., W. Lee, and Y. Liou, 2015: The kinematic and microphysical characteristics and associated precipitation efficiency of subtropical convection during SoWMEX/TiMREX. Mon. Wea. Rev., 143, 317-340, https://doi.org/10.1175/MWR-D-1400081.1.

Christiansen, B., 2007: Atmospheric circulation regimes: Can cluster analysis provide the number? J. Climate, 20, 2229-2250, https://doi.org/10.1175/JCLI4107.1. 
Chung, K.-S., W. Chang, L. Fillion, and M. Tanguay, 2013: Examination of situation-dependent background error covariances at the convective scale in the context of the ensemble Kalman filter. Mon. Wea. Rev., 141, 3369-3387, https://doi.org/10. 1175/MWR-D-12-00353.1.

Davis, C. A., and W.-C. Lee, 2012: Mesoscale analysis of heavy rainfall episodes from SoWMEX/TiMREX. J. Atmos. Sci., 69, 521-537, https://doi.org/10.1175/JAS-D-11-0120.1.

Dawson, D. T., M. Xue, J. A. Milbrandt, and M. K. Yau, 2010: Comparison of evaporation and cold pool development between single-moment and multimoment bulk microphysics schemes in idealized simulations of tornadic thunderstorms. Mon. Wea. Rev., 138, 1152-1171, https://doi.org/10.1175/ 2009MWR2956.1.

Dowell, D. C., L. J. Wicker, and C. Snyder, 2011: Ensemble Kalman filter assimilation of radar observations of the 8 May 2003 Oklahoma City supercell: Influences of reflectivity observations on storm-scale analyses. Mon. Wea. Rev., 139, 272-294, https://doi.org/10.1175/2010MWR3438.1.

Duda, J. D., X. Wang, F. Kong, and M. Xue, 2014: Using varied microphysics to account for uncertainty in warm-season QPF in a convection-allowing ensemble. Mon. Wea. Rev., 142, 2198-2219, https://doi.org/10.1175/MWR-D-13-00297.1.

Dudhia, J., 1989: Numerical study of convection observed during the winter monsoon experiment using a mesoscale twodimensional model. J. Atmos. Sci., 46, 3077-3107, https://doi. org/10.1175/1520-0469(1989)046<3077:NSOCOD>2.0.CO;2.

Durran, D. R., and M. Gingrich, 2014: Atmospheric predictability: Why butterflies are not of practical importance. J. Atmos. Sci., 71, 2476-2488, https://doi.org/10.1175/JAS-D-14-0007.1.

Ebert, E. E., 2008: Fuzzy verification of high-resolution gridded forecasts: A review and proposed framework. Meteor. Appl., 15, 51-64, https://doi.org/10.1002/met.25.

Errico, R. M., 1985: Spectra computed from a limited area grid. Mon. Wea. Rev., 113, 1554-1562, https://doi.org/10.1175/15200493(1985)113<1554:SCFALA > 2.0.CO;2.

Evensen, G., 1994: Sequential data assimilation with a nonlinear quasi-geostrophic model using Monte Carlo methods to forecast error statistics. J. Geophys. Res., 99, 10 143-10162, https://doi.org/10.1029/94JC00572.

Gilmore, M. S., J. M. Straka, and E. N. Rasmussen, 2004: Precipitation uncertainty due to variations in precipitation particle parameters within a simple microphysics scheme. Mon. Wea. Rev., 132, 2610-2627, https://doi.org/10.1175/MWR2810.1.

Gourley, J. J., R. A. Maddox, K. W. Howard, and D. W. Burgess, 2002: An exploratory multisensor technique for quantitative estimation of stratiform rainfall. J. Hydrometeor., 3, 166-180, https://doi.org/10.1175/1525-7541(2002)003<0166: AEMTFQ $>2.0 . \mathrm{CO} ; 2$.

Grell, G. A., and S. R. Freitas, 2014: A scale and aerosol aware stochastic convective parameterization for weather and air quality modeling. Atmos. Chem. Phys., 14, 5233-5250, https:/ doi.org/10.5194/acp-14-5233-2014.

Ha, S., J. Berner, and C. Snyder, 2015: A comparison of model error representations in mesoscale ensemble data assimilation. Mon. Wea. Rev., 143, 3893-3911, https://doi.org/10.1175/ MWR-D-14-00395.1.

Hong, S.-Y., and J.-O. J. Lim, 2006: The WRF Single-Moment 6Class Microphysics Scheme (WSM6). J. Korean Meteor. Soc., 42, 129-151.

—, Y. Noh, and J. Dudhia, 2006: A new vertical diffusion package with an explicit treatment of entrainment processes.
Mon. Wea. Rev., 134, 2318-2341, https://doi.org/10.1175/ MWR3199.1.

Jou, B. J. D., W. C. Lee, and R. H. Johnson, 2011: An overview of SoWMEX/TiMREX. The Global Monsoon System: Research and Forecasts, 2nd ed. Chang, C.-P., Ed., World Scientific, 303-318, https://doi.org/10.1142/9789814343411_0018.

Li, C.-H., J. Berner, J.-S. Hong, C.-T. Fong, and Y.-H. Kuo, 2020: The Taiwan WRF ensemble prediction system: Scientific description, model-error representation and performance results. Asia-Pac. J. Atmos. Sci., 56, 1-15, https://doi.org/10. 1007/s13143-019-00127-8.

Lim, K.-S. S., and S.-Y. Hong, 2010: Development of an effective double-moment cloud microphysics scheme with prognostic cloud condensation nuclei $(\mathrm{CCN})$ for weather and climate models. Mon. Wea. Rev., 138, 1587-1612, https://doi.org/10. 1175/2009MWR2968.1.

Lin, Y.-L., R. D. Farley, and H. D. Orville, 1983: Bulk parameterization of the snow field in a cloud model. J. Climate Appl. Meteor., 22, 1065-1092, https://doi.org/10.1175/15200450(1983)022<1065:BPOTSF $>2.0 . C O ; 2$.

Lupo, K. M., R. D. Torn, and S.-C. Yang, 2020: Evaluation of stochastic perturbed parameterization tendencies on convectivepermitting ensemble forecasts of heavy rainfall events in New York and Taiwan. Wea. Forecasting, 35, 5-24, https://doi.org/ 10.1175/WAF-D-19-0064.1.

Melhauser, C., and F. Zhang, 2012: Practical and intrinsic predictability of severe and convective weather at the mesoscales. $J$. Atmos. Sci., 69, 3350-3371, https://doi.org/10.1175/JAS-D-110315.1.

Meng, Z., and F. Zhang, 2007: Tests of an ensemble Kalman filter for mesoscale and regional-scale data assimilation. Part II: Imperfect model experiments. Mon. Wea. Rev., 135, 1403 1423, https://doi.org/10.1175/MWR3352.1.

Mlawer, E. J., S. J. Taubman, P. D. Brown, M. J. Iacono, and S. A. Clough, 1997: Radiative transfer for inhomogeneous atmospheres: RRTM, a validated correlated-k model for the longwave. J. Geophys. Res., 102, 16663-16682, https://doi. org/10.1029/97JD00237.

Morrison, H., and J. Milbrandt, 2011: Comparison of two-moment bulk microphysics schemes in idealized supercell thunderstorm simulations. Mon. Wea. Rev., 139, 1103-1130, https:// doi.org/10.1175/2010MWR3433.1.

— J. A. Curry, and V. I. Khvorostyanov, 2005: A new doublemoment microphysics parameterization for application in cloud and climate models. Part I: Description. J. Atmos. Sci., 62, 1665-1677, https://doi.org/10.1175/JAS3446.1.

— , G. Thompson, and V. Tatarskii, 2009: Impact of cloud microphysics on the development of trailing stratiform precipitation in a simulated squall line: Comparison of one- and two-moment schemes. Mon. Wea. Rev., 137, 991-1007, https://doi.org/10.1175/2008MWR2556.1.

- - and Coauthors, 2020: Confronting the challenge of modeling cloud and precipitation microphysics. J. Adv. Model Earth Syst., 12, e2019MS001689, https://doi.org/10.1029/2019MS001689.

Nielsen, E. R., and R. S. Schumacher, 2016: Using convectionallowing ensembles to understand the predictability of an extreme rainfall event. Mon. Wea. Rev., 144, 3651-3676, https://doi.org/10.1175/MWR-D-16-0083.1.

Putnam, B. J., M. Xue, Y. Jung, G. Zhang, and F. Kong, 2017a: Simulation of polarimetric radar variables from 2013 CAPS spring experiment storm-scale ensemble forecasts and evaluation of microphysics schemes. Mon. Wea. Rev., 145, 49-73, https://doi.org/10.1175/MWR-D-15-0415.1. 
$-,-\longrightarrow,-$ N. A. Snook, and G. Zhang, 2017b: Ensemble probabilistic prediction of a mesoscale convective system and associated polarimetric radar variables using single-moment and double-moment microphysics schemes and EnKF radar data assimilation. Mon. Wea. Rev., 145, 2257-2279, https://doi. org/10.1175/MWR-D-16-0162.1.

Romine, G. S., C. S. Schwartz, J. Berner, K. R. Fossell, C. Snyder, J. L. Anderson, and M. L. Weisman, 2014: Representing forecast error in a convection-permitting ensemble system. Mon. Wea. Rev., 142, 4519-4541, https://doi.org/10.1175/MWR-D14-00100.1.

Schumacher, R. S., and A. J. Clark, 2014: Evaluation of ensemble configurations for the analysis and prediction of heavy-rainproducing mesoscale convective systems. Mon. Wea. Rev., 142, 4108-4138, https://doi.org/10.1175/MWR-D-13-00357.1.

Selz, T., and G. C. Craig, 2015: Simulation of upscale error growth with a stochastic convection scheme. Geophys. Res. Lett., 42 , 3056-3062, https://doi.org/10.1002/2015GL063525.

Skamarock, W. C., and J. B. Klemp, 2008: A time-split nonhydrostatic atmospheric model for weather research and forecasting applications. J. Comput. Phys., 227, 3465-3485, https://doi. org/10.1016/j.jcp.2007.01.037.

Snyder, C., and F. Zhang, 2003: Assimilation of simulated Doppler radar observations with an ensemble Kalman filter. Mon. Wea. Rev., 131, 1663-1677, https://doi.org/10.1175//2555.1.

Ştefănescu, S. E., L. Berre, and M. B. Pereira, 2006: The evolution of dispersion spectra and the evaluation of model differences in an ensemble estimation of error statistics for a limited-area analysis. Mon. Wea. Rev., 134, 3456-3478, https://doi.org/10. 1175/MWR3230.1.

Steiner, M., R. A. Houze, and S. E. Yuter, 1995: Climatological characterization of three-dimensional storm structure from operational radar and rain gauge data. J. Appl. Meteor., 34, 1978-2007, https://doi.org/10.1175/1520-0450(1995)034<1978: CCOTDS $>2.0 . \mathrm{CO} ; 2$.

Stensrud, D. J., J. Bao, and T. T. Warner, 2000: Using initial condition and model physics perturbations in short-range ensemble simulations of mesoscale convective systems. Mon. Wea. Rev., 128, 2077-2107, https://doi.org/10.1175/1520-0493(2000)128 $<2077$ :UICAMP>2.0.CO;2.

Sun, J., H. Wang, W. Tong, Y. Zhang, C. Lin, and D. Xu, 2016: Comparison of the impacts of momentum control variables on high-resolution variational data assimilation and precipitation forecasting. Mon. Wea. Rev., 144, 149-169, https://doi. org/10.1175/MWR-D-14-00205.1.

Tan, Z., F. Zhang, R. Rotunno, and C. Snyder, 2004: Mesoscale predictability of moist baroclinic waves: Experiments with parameterized convection. J. Atmos. Sci, 61, 1794-1804, https:// doi.org/10.1175/1520-0469(2004)061<1794:MPOMBW>2.0.CO;2.

Tao, W.-K., J. Simpson, and M. McCumber, 1989: An ice-water saturation adjustment. Mon. Wea. Rev., 117, 231-235, https:// doi.org/10.1175/1520-0493(1989)117<0231:AIWSA > 2.0.CO;2.

— , and Coauthors, 2003: Microphysics, radiation and surface processes in the Goddard Cumulus Ensemble (GCE) model. Meteor. Atmos. Phys., 82, 97-137, https://doi.org/10.1007/ s00703-001-0594-7.

Tapiador, F. J., and Coauthors, 2012: A comparison of perturbed initial conditions and multiphysics ensembles in a severe weather episode in Spain. J. Appl. Meteor. Climatol., 51, 489504, https://doi.org/10.1175/JAMC-D-11-041.1.
Toth, Z., and E. Kalnay, 1997: Ensemble forecasting at NCEP and the breeding method. Mon. Wea. Rev., 125, 3297-3319, https://doi.org/10.1175/1520-0493(1997)125<3297:EFANAT> 2.0.CO;2.

Tu, C.-C., Y.-L. Chen, C.-S. Chen, P.-L. Lin, and P.-H. Lin, 2014: A comparison of two heavy rainfall events during the Terrain-Influenced Monsoon Rainfall Experiment (TiMREX) 2008. Mon. Wea. Rev., 142, 2436-2463, https://doi.org/10.1175/ MWR-D-13-00293.1.

Ulbrich, C. W., 1983: Natural variations in the analytical form of the raindrop size distribution. J. Climate Appl. Meteor., 22, 1764-1775, https://doi.org/10.1175/1520-0450(1983)022<1764: NVITAF $>2.0 . C O ; 2$.

Wang, H., T. Auligne, and H. Morrison, 2012: Impact of microphysics scheme complexity on the propagation of initial perturbations. Mon. Wea. Rev., 140, 2287-2296, https://doi.org/ 10.1175/MWR-D-12-00005.1.

Xu, W., E. J. Zipser, Y.-L. Chen, C. Liu, Y.-C. Liou, W.-C. Lee, and B. J.-D. Jou, 2012: An orography-associated extreme rainfall event during TiMREX: Initiation, storm evolution, and maintenance. Mon. Wea. Rev., 140, 2555-2574, https:// doi.org/10.1175/MWR-D-11-00208.1.

Xue, M., Y. Jung, and G. Zhang, 2010: State estimation of convective storms with a two-moment microphysics scheme and an ensemble Kalman filter: Experiments with simulated radar data. Quart. J. Roy. Meteor. Soc., 136, 685-700, https://doi. org/10.1002/qj.593.

Yang, S.-C., S.-H. Chen, S.-Y. Chen, C.-Y. Huang, and C.-S. Chen, 2014: Evaluating the impact of the COSMIC-RO bending angle data on predicting the heavy precipitation episode on 16 June 2008 during SoWMEX-IOP8. Mon. Wea. Rev., 142, 4139-4163, https://doi.org/10.1175/MWR-D-13-00275.1.

— Z Z. Huang, C. Huang, C. Tsai, and T. Yeh, 2020: A case study on the impact of ensemble data assimilation with GNSS-Zenith total delay and radar data on heavy rainfall prediction. Mon. Wea. Rev., 148, 1075-1098, https://doi.org/ 10.1175/MWR-D-18-0418.1.

You, C.-R., K.-S. Chung, and C.-C. Tsai, 2020: Evaluating the performance of a convection-permitting model by using dualpolarimetric radar parameters: Case study of SoWMEX IOP8. Remote Sens., 12, 3004, https://doi.org/10.3390/rs12183004.

Yussouf, N., and D. J. Stensrud, 2012: Comparison of single-parameter and multiparameter ensembles for assimilation of radar observations using the ensemble Kalman filter. Mon. Wea. Rev., 140, 562-586, https://doi.org/10.1175/MWR-D-10-05074.1.

Zhang, F., 2005: Dynamics and structure of mesoscale error covariance of a winter cyclone estimated through short-range ensemble forecasts. Mon. Wea. Rev., 133, 2876-2893, https:// doi.org/10.1175/MWR3009.1.

— , C. Snyder, and R. Rotunno, 2002: Mesoscale predictability of the "surprise" snowstorm of 24-25 January 2000. Mon. Wea. Rev., 130, 1617-1632, https://doi.org/10.1175/1520-0493 (2002)130<1617:MPOTSS >2.0.CO;2.

,-- , and 2003: Effects of moist convection on mesoscale predictability. J. Atmos. Sci., 60, 1173-1185, https://doi. org/10.1175/1520-0469(2003)060<1173:EOMCOM>2.0.CO;2.

—, N. Bei, R. Rotunno, C. Snyder, and C. C. Epifanio, 2007: Mesoscale predictability of moist baroclinic waves: Convection-permitting experiments and multistage error growth dynamics. J. Atmos. Sci., 64, 3579-3594, https://doi.org/10. 1175/JAS4028.1. 